\title{
Methodology and Historical Perspective of a Hall Thruster Efficiency Analysis
}

\author{
Daniel L. Brown,, C. William Larson,, \pm and Brian E. Beal $\stackrel{ \pm}{ \pm}$ \\ U.S. Air Force Research Laboratory, Edwards Air Force Base, California 93524 \\ and \\ Alec D. Gallimore $\underline{\underline{\S}}$ \\ University of Michigan, Ann Arbor, Michigan 48109 \\ DOI: $\underline{10.2514 / 1.38092}$
}

\begin{abstract}
A Hall thruster performance architecture was developed based on separation of the total thrust directed along thruster centerline into mass-weighted and momentum-weighted terms. With this formulation, the total thruster efficiency equation was analytically decomposed to explicitly account for the effects of energy conversion losses, plume divergence, and the velocity distribution function of the propellant jet. Thruster efficiency is defined as the product of 1) energy efficiency, 2) propellant efficiency, and 3) beam efficiency. Energy efficiency comprises losses due to ionization processes and losses that manifest as Joule heating, and contains no information about the vector properties of the jet. Propellant efficiency incorporates losses from dispersion in the jet composition and is unity for $100 \%$ ionization to a single ion species. The effect of neutrals on dispersion of the jet velocity distribution function in propellant efficiency is introduced in the neutral-gain utilization. The beam efficiency accounts for divergence of the jet and is ideal when the ion velocity vectors are parallel to the thrust axis. Plume divergence is defined as a momentum-weighted term, and the approximation as a charge-weighted term is characterized. The efficiency architecture is derived from first principles and is applicable to all propulsion employing electrostatic acceleration, including Hall thrusters and ion thrusters. Distinctions and similarities to several past methodologies are discussed, including past ion thruster analyses, early Russian performance studies, and contemporary architectures. To illustrate the potential for enhanced understanding of loss mechanisms and ionization processes with an array of farfield plume diagnostics, a case study is presented of low-discharge voltage operation from a 6 kW laboratory Hall thruster.
\end{abstract}

\begin{tabular}{ll} 
& \multicolumn{1}{c}{ Nomenclature } \\
$A$ & $=$ spherical shell surface area element in the plume \\
$E_{1}$ & $=$ voltage exchange parameter \\
$E_{2}$ & $=$ mass exchange parameter \\
$\mathbf{F}$ & $=$ thrust density vector in the plume \\
$\mathcal{F}$ & $=$ Faraday constant, $96,485 \mathrm{C} / \mathrm{mol}$ of charge \\
$f_{j}^{*}$ & $=$ normalized ion mass flow fraction of $j$ th ion species \\
$f(\mathbf{v})$ & $=$ velocity distribution function of ions and neutrals \\
$g$ & $=$ Earth's gravitational constant at sea level, $9.806 \mathrm{~m} / \mathrm{s}^{2}$ \\
$I_{\text {Axial }}$ & $=$ axial component of beam current parallel to thruster \\
& centerline \\
$I_{\text {Beam }}=$ & integrated beam current \\
$I_{d}$ & $=$ anode discharge current \\
$I_{\mathrm{sp}}$ & $=$ total specific impulse \\
$J(\theta)$ & $=$ current density in the plume at angular position $\theta$ \\
$j$ & $=$ propellant charge state index, $0,1,2,3$, etc., for Xe $\mathrm{Xe}^{0}$ \\
$\mathcal{M}$ & $=$ Xe $\mathrm{e}^{+1}, \mathrm{Xe}^{+2}, \mathrm{Xe} \mathrm{e}^{+3}$ \\
&
\end{tabular}

Received 18 April 2008; revision received 1 August 2009; accepted for publication 4 August 2009. This material is declared a work of the U.S. Government and is not subject to copyright protection in the United States. Copies of this paper may be made for personal or internal use, on condition that the copier pay the $\$ 10.00$ per-copy fee to the Copyright Clearance Center, Inc., 222 Rosewood Drive, Danvers, MA 01923; include the code 0748-4658/ 09 and $\$ 10.00$ in correspondence with the CCC.

*Research Scientist, Propulsion Directorate, Spacecraft Branch; Daniel. Brown@edwards.af.mil. Member AIAA.

${ }^{\dagger}$ Research Scientist, Propulsion Directorate, Spacecraft Branch; Carl. Larson@edwards.af.mil. Senior Member AIAA.

Frogram Manager, Propulsion Directorate, Spacecraft Branch; Brian. Beal@edwards.af.mil. Member AIAA.

${ }^{\S}$ Laboratory Director, Plasmadynamics and Electric Propulsion Laboratory; Professor, Department of Aerospace Engineering; Associate Dean, Horace H. Rackham School of Graduate Studies; Alec.Gallimore@umich. edu. Associate Fellow AIAA. $\dot{m}_{i} \quad=$ mass flow rate of ions, where $\sum \dot{m}_{j}=\dot{m}_{i}$ for $j=1$ to the $j$ th ion species

$\dot{m}_{j} \quad=$ mass flow rate of $j$ th species

$\dot{m}_{T}=$ total mass flow rate to the anode and cathode, where $\sum \dot{m}_{j}=\dot{m}_{T}$ for $j=0$ to the $j$ th ion species

$\dot{m}(\theta)=$ mass flux at angular position $\theta$

$P_{d} \quad=$ discharge power to the anode

$P_{\text {jet }}=$ jet power

$P_{\text {loss }} \quad=$ power lost to Joule heating processes

$P_{\min }=$ minimum power required to sustain ionization

$Q \quad=$ average charge of propellant ions

$R=$ downstream measurement radius from the axis of rotation

$r \quad=$ fraction of electron current to the anode, electron recycle fraction

$T \quad=$ component of thrust vector directed along thruster centerline

$V_{a} \quad=$ most probable ion acceleration voltage

$V_{d} \quad=$ anode discharge voltage

$\overline{\mathbf{v}}=$ average exit velocity of the velocity distribution function over velocity space $d \mathbf{v}$ at angular position $\theta$

$\bar{v}, \overline{v^{2}}=$ average propellant velocity, squared propellant velocity

$\bar{v}_{i}, \overline{v_{i}^{2}}=$ average ion velocity, squared ion velocity

$v_{j} \quad=$ exit speed of $j$ th species

$\bar{v}(\theta)=$ radial component of $\overline{\mathbf{v}}$ in hemispherical coordinates from thruster centerline at angular position $\theta$

$y_{j}=$ normalized speed ratio of the $j$ th species $=v_{j} /\left|v_{1}\right|$

$Z_{j} \quad=$ ion charge state $=1,2,3$ for $\mathrm{Xe}^{+1}, \mathrm{Xe}^{+2}, \mathrm{Xe}^{+3}$

$\beta=$ fractional loss of acceleration potential

$\delta V_{j}=$ acceleration potential of $j$ th ion species

$\varepsilon_{B}=$ average ionization cost per beam ion

$\varepsilon_{B, \min }=$ minimum ionization cost per beam ion

$\varepsilon_{j}=$ ionization potential of $j$ th ion species $(12,33,65 \mathrm{eV}$ from neutral ground state for Xe) 


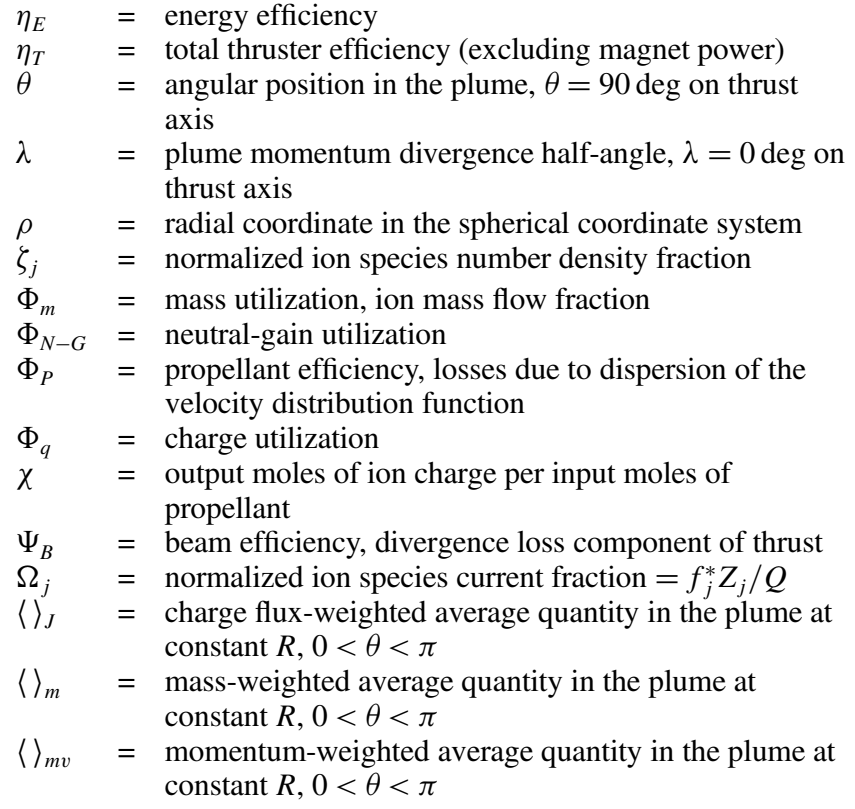

\section{Introduction}

Q TANDARDIZATION of experimental methods, facilities, diagnostic apparatus, and efficiency analysis has previously been proposed in the electric propulsion community [1]. An efficiency architecture is presented that is based on a consistent set of definitions, conservation of energy, conservation of mass and charge, and Newton's second law. The relationships between performance data, telemetry $\left(V_{d}, I_{d}\right.$, and $\left.\dot{m}_{T}\right)$, and plume measurements are summarized and new correlations are developed.

In this paper, we present the basis for analytical separation of total thruster efficiency into the product of energy efficiency, propellant efficiency, and beam efficiency, which are less than unity under all operating conditions. Separating utilization efficiencies in this manner isolates performance losses in terms of energy losses that lead to Joule heating, dispersion of the jet velocity distribution function (VDF), and loss of thrust due to plume divergence. Although these processes are physically coupled, the effects on performance may be mathematically isolated.

Historical perspective of early ion thruster analyses, methodologies developed in the former Soviet Union, and a brief description of contemporary efficiency models are discussed in relation to the presented architecture. The architecture is distinctive in formulating the axial component of thrust as the product of mass-weighted and momentum-weighted quantities, and introduces a new definition of propellant efficiency that incorporates multiple ion species and the effects of nonionized propellant. Including cathode flow in the performance analysis is vital to accurately assess loss mechanisms over a wide range of thruster operation. Whereas cathode flow rate is typically $7 \%$ of the anode flow, recent investigations of lowdischarge voltage Hall thruster operation indicate total thruster efficiency optimizes at higher cathode flow rate [2] ]. In addition, a fraction of this cathode flow may ionize and must be accounted for in far-field plume measurements.

Thruster performance parameters, including thrust to power $T / P$ and total specific impulse $I_{\mathrm{sp}}$, are formulated in terms of utilization efficiencies to provide a higher level of confidence in comparisons between plume measurements and thrust measurements. Experimental thrust and plume measurements from a $6 \mathrm{~kW}$ laboratory model Hall thruster are studied to illustrate the fidelity of the proposed analytical model and to demonstrate the utility of combining results from a set of diagnostics in determining Hall thruster performance. Power losses and beam ionization cost are studied using the energy efficiency and are compared to the minimum power required to sustain the discharge ion species composition. Low-voltage discharge processes are briefly discussed with regard to past investigations and simulations.

\section{Historical Perspective and Recent Efforts}

Investigations of ion acceleration and electron transport using Hall thruster technology began in the early 1960s in the United States and former Soviet Union (USSR) [3-13]. The focus of U.S. electric propulsion research shifted primarily to ion thruster technology in the early 1970s [14], whereas investigations in the USSR continued Hall thruster advancements throughout the following decades [15-17].

Analytical factorization of ion thruster efficiency was described as early as 1975 by Masek et al. in a review of ion thruster performance [18]. Anode thrust efficiency was factored into the product of energy efficiency and propellant utilization efficiency using Newton's second law, with terms accounting for losses due to doubly charged ions and beam divergence. However, the derivation was condensed and an explanation for the treatment of beam divergence and multiply charged ions was not presented. The methodology was not widely adopted or cited in the ion thruster community and is absent in modern analysis.

In the 1990s, the manifestation of Russian Hall thruster technology in the Western and Japanese spacecraft communities catalyzed a resurgence of Hall thruster research [19-24]. Technology transfer that began in the early 1990s brought invaluable benefits and advancements to Western Hall thruster development, but much of the earlier Soviet progress in Hall thruster research that was published in the Russian language was not translated. The limited availability of translated documents from this extensive literature inevitably impeded the transmission of knowledge and progress. As a result, several important contributions from Russian research have not been widely disseminated in the West, including the analytical factorization of anode thrust efficiency.

Factorization of Hall thruster efficiency was outlined in a manual on stationary plasma thrusters by Belan et al. from the Kharkov Aviation Institute in 1989 [25]. This seminal document was later referenced and the performance methodology summarized by Bugrova et al. [26] without explicitly stating the nature of the earlier derivation. Kim's [27] highly cited 1998 paper on processes that determine Hall thruster efficiency and other contemporary publications [28-30] continued the elaboration of the Kharkov Aviation Institute methodology. These approaches show similarities to the analysis presented here and demonstrated relationships between experimental variables and plasma phenomena that affect thruster performance.

A textbook by Grishin and Leskov [31] analyzed thruster performance based on energy efficiency and thrust efficiency. The ratio of thrust efficiency to energy efficiency was asserted to describe the velocity dispersion in magnitude and direction. This ratio will be derived from first principles in the following section, where it will become apparent that the ratio is equivalent to beam efficiency and propellant efficiency, which capture losses resulting from plume divergence, incomplete ionization, and the production of multiply charged ions.

The term propellant utilization efficiency has been used in at least three different ways in the literature. Most commonly as 1) the ionization fraction, as 2) the fraction of momentum carried by ions [15], or as 3) the ratio of output moles of charge to the input moles of propellant [32], which is equivalent to the product of the ion mass flow fraction and average ion charge. Although the definitions of voltage and current utilization are standardized, a consistent description of propellant utilization has not emerged.

In the post-1990 era, numerous efficiency analysis frameworks and modifications have been proposed [33-37], including notable studies by Komurasaki and Arakawa [38], Ahedo et al. [39], and Hofer et al. $[40,41]$. The difference between the proposed architecture with past ion thruster studies, the analytical factorization in Russian literature, and the post-1990 methodologies varies in each case. Dissimilarities arise due to varying levels of completeness regarding the treatment of multiply charged ions, beam divergence, and the effect of neutral propellant on dispersion of the jet VDF. In some instances, the effects of these loss mechanisms are neglected or inserted as a utilization efficiency without rigorously factoring the term from the thrust efficiency equation. Utilization efficiencies in 
the performance model presented in this paper are analytically separated from the total thruster efficiency and are formulated to minimize the introduction of new terminology. The primary differences with all previous methodologies is quantifying the effect of neutrals on dispersion of the VDF in the neutral-gain utilization and decomposing total thrust into the product of mass-weighted and momentum-weighted quantities. Three appendices are included to define plume averaged terms and detail the derivation of propellant efficiency and beam efficiency.

This analytical tool is not meant to predict Hall thruster physics or plasma properties in the same manner as a computational model. Whereas numerical simulations typically determine plasma properties throughout the plume and/or performance attributes based on a particle source model, this analysis technique employs performance measurements and global plume characteristics to experimentally determine physical processes and relationships that are difficult to measure directly.

\section{Hall Thruster Performance Architecture}

\section{A. Decoupling Energy Efficiency, Beam Efficiency,} and Propellant Efficiency

The total thrust generated by a Hall thruster is primarily a function of electromagnetic forces and, to a much lesser degree, gas dynamic forces. Downstream of the primary ionization and acceleration regions, the total resultant thrust may be found from Eq. (1) through integration of the thrust density vector $\mathbf{F}$ throughout the plume:

$$
T \hat{\rho}=\iint \mathbf{F} \cdot \hat{\rho} \mathrm{d} A
$$

This idealized description suffers from numerous experimental difficulties and uncertainties. Although Eq. (1) may be valid in the space environment, facility effects inherent in ground tests result in significant scattering in the plume and potentially increased thrust from neutral ingestion. Measurements of thrust density throughout the Hall effect thruster plume are extremely difficult, but may be viable using an impact target plate [42].

The conventional inverted pendulum thrust stand measures the component of thrust directed along the thruster centerline axis. Careful thruster alignment and uniform propellant injection generally result in an axisymmetric plume with negligible deviations between the resultant thrust vector direction and the thruster centerline axis. For an axisymmetric plume, the steady-state scalar component of thrust directed along the thruster centerline is formulated in Eq. (2). The total thrust may be factored into the product of total mass flow rate, mass-weighted average velocity, and momentum-weighted average divergence using the definitions listed in Appendix A. Thrust is typically defined as the product of averaged quantities without mathematically separating terms from the thrust integral or specifying the nature of the average. Although the fraction of thrust generated by nonionized propellant is negligible, a fraction of the cathode flow may be ionized and the total propellant flow is necessary to characterize performance over a wide range of thruster operation:

$$
T=2 \pi R^{2} \int_{0}^{\pi / 2} \dot{m}(\theta) \bar{v}(\theta) \cos (\theta) \sin (\theta) \mathrm{d} \theta=\dot{m}_{T}\langle\bar{v}\rangle_{m}\langle\cos (\theta)\rangle_{m v}
$$

In Eq. (3), the standard definition of total thruster efficiency is expressed in terms of thruster telemetry and measured thrust. Total efficiency $\eta_{T}$ is decomposed into the product of energy efficiency $\eta_{E}$, propellant efficiency $\Phi_{P}$, and beam efficiency $\Psi_{B}$ using the definition of jet kinetic energy, Newton's second law, and the mass-weighted average squared velocity:

$$
\eta_{T}=\frac{\frac{1}{2} T^{2}}{\dot{m}_{T} P_{d}}=\frac{\frac{1}{2}\left(\dot{m}_{T}\langle v\rangle_{m}\langle\cos (\theta)\rangle_{m v}\right)^{2}}{\dot{m}_{T} P_{d}}=\eta_{E} \Phi_{P} \Psi_{B}
$$

Energy efficiency in Eq. (4) characterizes the conversion of input anode electrical energy to jet kinetic energy and contains all information about losses that ultimately appear as ohmic heating, excitation, radiation, and ionization losses in the discharge. In this analysis, the jet power accounts for the energy of neutral propellant and includes the total propellant flow rate, whereas most definitions only incorporate the beam ion energy:

$$
\eta_{E}=\frac{P_{\mathrm{jet}}}{P_{d}}=\frac{\frac{1}{2} \dot{m}_{T}\left\langle\overline{v^{2}}\right\rangle_{m}}{V_{d} I_{d}}
$$

Jet momentum losses due to beam divergence are quantified using the momentum-weighted average $\cos (\theta)$ in Eq. (5). This formulation is similar to the focusing efficiency described by Kim [27], but is naturally expressed as a momentum-weighted average quantity from the formulation of thrust in Eq. (2):

$$
\Psi_{B}=\langle\cos (\theta)\rangle_{m v}^{2}
$$

Propellant efficiency in Eq. (6) is the mathematical relationship between the particle momentum and the jet kinetic energy. It contains all loss information associated with dispersion of the jet VDF due to incomplete ionization and the presence of multiple ion species with widely varying velocities. This ratio is unity for $100 \%$ ionization to a single ion species:

$$
\Phi_{P}=\frac{\langle\bar{v}\rangle_{m}^{2}}{\left\langle\overline{v^{2}}\right\rangle_{m}}
$$

The factors affecting propellant efficiency, energy efficiency, and beam efficiency will be discussed in the following sections. Propellant efficiency will be decomposed into mass and charge utilization efficiencies, and the neutral-gain utilization is introduced to characterize the effect of neutral propellant on dispersion of the VDF. Next, energy efficiency is separated into the product of voltage utilization and current utilization using $\chi$. Beam efficiency will then be analyzed with regard for the distinction between momentumweighted divergence and current-weighted plume divergence.

\section{B. Decoupling Mass Utilization, Charge Utilization, and Neutral-Gain Utilization from Propellant Efficiency}

The influence of nonuniform velocity distribution on propellant efficiency due to multiple ion species and nonionized propellant is expressed in Eq. (7). Propellant efficiency is separated into the product of mass utilization $\Phi_{m}$, charge utilization $\Phi_{q}$, and neutralgain utilization $\Phi_{N-G}$ using the definitions in Appendix $\underline{B}$. The propellant efficiency is separated in this way to maintain a consistent definition of mass utilization and charge utilization with previous methodologies [40], and to isolate effects resulting from the nonionized propellant flow:

$$
\Phi_{P}=\left(\frac{\left\langle\bar{v}_{i}\right\rangle_{m}^{2}}{\left\langle\overline{v_{i}^{2}}\right\rangle_{m}}\right)\left(\frac{\langle\bar{v}\rangle_{m}^{2}}{\left\langle\overline{v_{i}}\right\rangle_{m}^{2}} \frac{\left\langle\overline{v_{i}^{2}}\right\rangle_{m}}{\left\langle\overline{v^{2}}\right\rangle_{m}}\right)=\Phi_{q} \Phi_{m} \Phi_{N-G}
$$

The standard definition of charge utilization is formulated from the first term in brackets in Eq. (7). Charge utilization is expressed in Eq. (8) using species current fractions as obtained from an ExB probe and is unity for ionization to a single ion species. Charge utilization is also written using ion species mass flow fractions in Eq. (8). Ion mass flow fractions are defined according to Eq. (9):

$$
\begin{gathered}
\Phi_{q}=\left(\frac{\left\langle\overline{v_{i}}\right\rangle_{m}^{2}}{\left\langle\overline{v_{i}^{2}}\right\rangle_{m}}\right)=\frac{\left[\sum_{j=1}\left(\Omega_{j} / \sqrt{Z_{j}}\right)\right]^{2}}{\sum_{j=1}\left(\Omega_{j} / Z_{j}\right)}=\frac{\left(\sum_{j=1} f_{j}^{*} \sqrt{Z_{j}}\right)^{2}}{\sum_{j=1} f_{j}^{*} Z_{j}} \\
f_{j}^{*}=\frac{\dot{m}_{j}}{\sum_{j=1} \dot{m}_{j}}
\end{gathered}
$$

It is important to note the distinction between ion current fractions, ion mass flow fractions, and ion species number fractions. The ion current fractions are determined directly from ExB probe traces. Ion 
species number fractions are based on particle number density, and are commonly reported for incorporation in numerical simulations. The ion mass flow fraction is a more suitable figure of merit for experimental plume studies, because it is related to the ion species momentum in the plume. The average ion charge $Q$ in Eq. (10) is expressed in terms of ion current fractions, ion flow fractions, and ion species fractions:

$$
Q=\sum_{j=1} f_{j}^{*} Z_{j}=\left(\sum_{j=1} \frac{\Omega_{j}}{Z_{j}}\right)^{-1}=\frac{\sum_{j=1} \zeta_{j} Z_{j}^{3 / 2}}{\sum_{j=1} \zeta_{j} Z_{j}^{1 / 2}}
$$

The mass utilization and neutral-gain utilization are developed from the second term in brackets in Eq. (7). Mass utilization is defined as the ratio of ion mass flow rate to total mass flow rate in Eq. (11), and is calculated using beam current from a Faraday probe in conjunction with the average ion charge from an ExB probe. If only the anode mass flow rate is used, it is possible for this term to be greater than unity when a significant fraction of the cathode flow is ionized in the plume:

$$
\Phi_{m}=\frac{\sum_{j=1} \dot{m}_{j}}{\sum_{j=0} \dot{m}_{j}}=\frac{\dot{m}_{i}}{\dot{m}_{T}}=\frac{I_{\mathrm{Beam}}}{\dot{m}_{T} Q} \frac{\mathcal{M}}{\mathcal{F}}
$$

The effects of neutral propellant on dispersion of the jet VDF are quantified in Eq. (12). This term is always greater than one, and is indicative of the thrust and energy gained due to the speed of the neutrals. The neutral-gain utilization is a strong function of the normalized neutral speed and mass utilization. The normalized neutral speed $y_{0}$ is typically less than 0.05 for most Hall thrusters and operating conditions $[43,44]$, which results in a neutral-grain utilization of less than 1.02 . Neutral-gain utilization is expected to increase for low-discharge voltage, high-power thruster operation, and anode propellant injection with a large bulk axial velocity component. Minimizing this utilization is critical for high-performance operation, because it increases with decreased ionization and decreased neutral residence time in the discharge channel:

$$
\Phi_{N-G} \approx 1+2 y_{0} \frac{\left(1-\Phi_{m}\right)}{\Phi_{m} \sqrt{Q \Phi_{q}}}
$$

The factorization of propellant efficiency is detailed in Appendix $\underline{B}$, along with a more detailed characterization of the neutral-gain utilization for variation in $y_{0}, \Phi_{m}$, and ion species composition.

\section{Decoupling Voltage Utilization and Current Utilization from Energy Efficiency}

Energy efficiency is factored in Eq. (13) as the product of voltage utilization $(1-\beta)$, and current utilization $(1-r)$. It is convenient to introduce $\chi$, which is defined in Eq. (14) as the ratio of output moles of charge to input moles of propellant. Although $\chi$ cancels in the energy efficiency term, it is shown in Eqs. (18) and (19) to reveal the physical nature of the voltage and current utilization inherent in the thrust efficiency:

$$
\begin{aligned}
\eta_{E} & =\frac{\frac{1}{2} \dot{m}_{T}\left\langle\overline{v^{2}}\right\rangle_{m}}{P_{d}}=\left[\frac{\frac{1}{2}\left\langle\overline{v^{2}}\right\rangle_{m}}{(\mathcal{F} / \mathcal{M}) V_{d}}\right]\left[\frac{\dot{m}_{T}}{I_{d}} \frac{\mathcal{F}}{\mathcal{M}}\right]=[\chi(1-\beta)]\left[\frac{(1-r)}{\chi}\right] \\
& =(1-\beta)(1-r)
\end{aligned}
$$

where, by definition,

$$
\chi=\frac{\sum_{j=1} \dot{m}_{j} Z_{j}}{\sum_{j=0} \dot{m}_{j}}=\frac{\sum_{j=1} \dot{m}_{j} \sum_{j=1} f_{j}^{*} Z_{j}}{\dot{m}_{T}}=\Phi_{m} Q
$$

Equation (15) transforms the first term in brackets of Eq. (13) into an expression that contains explicit utilization of acceleration potential for each ion species, $\delta V_{j} / V_{d}$. A high-accuracy ExB probe measurement of ion mass flow fractions and estimation of ion acceleration potentials would enable a voltage utilization to be calculated for each ion species. The ratio of average particle specific kinetic energy to average ion specific kinetic energy in Eq. (15) is shown to be approximately equal to $\Phi_{m}$ in Eq. (16). The bracketed quantity in Eq. (16) is very close to unity under all reasonable conditions of Hall thruster operation due to the low value of $y_{0}$ in the numerator, since $y_{0}^{2}\left(1-\Phi_{m}\right)<1 \times 10^{-4}$ for experimental measurements of $y_{0}<0.05[43,44]$. Therefore, the approximation $\left\langle\overline{v^{2}}\right\rangle_{m} /\left\langle\overline{v_{i}^{2}}\right\rangle_{m} \approx \Phi_{m}$ is accurate to better than 1 in 10,000 :

$$
\frac{\frac{1}{2}\left\langle\overline{v_{i}^{2}}\right\rangle_{m}}{(\mathcal{F} / \mathcal{M}) V_{d}} \frac{\left\langle\overline{v^{2}}\right\rangle_{m}}{\left\langle\overline{v_{i}^{2}}\right\rangle_{m}} \approx \frac{\frac{1}{2} \Phi_{m}}{(\mathcal{F} / \mathcal{M}) V_{d}} \sum_{j=1}\left(\frac{\dot{m}_{j}}{\dot{m}_{i}} v_{j}^{2}\right)=\Phi_{m} \sum_{j=1}\left(f_{j}^{*} Z_{j} \frac{\delta V_{j}}{V_{d}}\right)
$$

where

$$
\begin{gathered}
\frac{\left\langle\overline{v^{2}}\right\rangle_{m}}{\left\langle\overline{v_{i}^{2}}\right\rangle_{m}}=\frac{\sum_{j=0}\left[\left(\dot{m}_{j} / \dot{m}_{T}\right) v_{j}^{2}\right]}{\sum_{j=1}\left[\left(\dot{m}_{j} / \dot{m}_{i}\right) v_{j}^{2}\right]}=\Phi_{m}\left[1+\frac{y_{0}^{2}\left(1-\Phi_{m}\right)}{\chi}\right] \approx \Phi_{m} \\
v_{j}=\sqrt{2 Z_{j} \delta V_{j}\left(\frac{\mathcal{F}}{\mathcal{M}}\right)}
\end{gathered}
$$

To simplify the analysis, all ions are considered to be created in the same zone for which the length is small compared to the acceleration length, such that $V_{a}=\delta V_{j} \approx$ constant. Previous investigations by Kim and Gallimore [45] and King [46] found that species-dependent energy to charge ratios varied by tens of volts using different types of energy analyzers. This variation in energy to charge ratio is less than $10 \%$ of the typical discharge voltage. According to Hofer [47], the approximation will have a negligible effect on accuracy because the plume is predominantly composed of singly ionized xenon. The velocity of neutrals and each ion species is approximated with a delta function distribution of velocities, such that the ion species kinetic energies are proportional to their charge and the ion velocity ratio magnitudes are $\left|y_{j}\right|=\left(Z_{j}\right)^{1 / 2}$. To the authors' knowledge, this approximation is consistent with all other performance architectures. Therefore, the most probable ion acceleration potential $V_{a}$, as measured with a retarding potential analyzer (RPA), enables the first term in brackets of Eq. (13) to be expressed in terms of the average voltage utilization efficiency and $\chi$ in Eq. (18). The average voltage utilization in Eq. (18) compares the most probable acceleration potential of ions with the applied anode potential, and is unity for ionization at the anode face where ions are accelerated through the entire anode potential:

$$
\frac{\frac{1}{2}\left\langle\overline{v^{2}}\right\rangle_{m}}{(\mathcal{F} / \mathcal{M}) V_{d}} \approx \Phi_{m} \frac{V_{a}}{V_{d}} \sum_{j=1}\left(f_{j}^{*} Z_{j}\right)=\Phi_{m}(1-\beta) Q=(1-\beta) \chi
$$

The second bracketed term in Eq. (13) is transformed in Eq. (19) into an expression containing the current utilization efficiency and $\chi$. Current utilization efficiency is the fraction of cathode electron flow that electrically neutralizes the accelerated positive ions in the plume, and is calculated as the ratio of ion beam current $I_{\text {Beam }}$ to discharge current $I_{d}$ :

$$
\begin{gathered}
\frac{\dot{m}_{T}}{I_{d}} \frac{\mathcal{F}}{\mathcal{M}}=\frac{\dot{m}_{T}(\mathcal{F} / \mathcal{M}) \chi}{I_{d}} \frac{1}{\chi}=\frac{I_{\text {Beam }}}{I_{d}} \frac{1}{\chi}=\frac{(1-r)}{\chi} \\
I_{\text {Beam }}=\sum_{j=1} \dot{m}_{j} Z_{j} \frac{\mathcal{F}}{\mathcal{M}}=\dot{m}_{T} \chi \frac{\mathcal{F}}{\mathcal{M}}
\end{gathered}
$$

The fraction of electron current traveling to the anode $r$ leads to propellant ionization, excitation, and ohmic heating of the thruster due to wall collisions. The minimum power $P_{\min }$ that is required to 
generate a given ion species composition is expressed in Eq. (21), and the corresponding minimum ionization $\operatorname{cost} \varepsilon_{B \text {,min }}$ is expressed in Eq. (22):

$$
\begin{gathered}
P_{\text {min }}=\frac{\mathcal{F}}{\mathcal{M}} \sum_{j=1}\left(\dot{m}_{j} Z_{j} \varepsilon_{j}\right)=\frac{I_{\text {Beam }}}{Q} \sum_{j=1}\left(f_{j}^{*} Z_{j} \varepsilon_{j}\right) \\
\varepsilon_{B, \text { min }}=\frac{P_{\text {min }}}{I_{\text {Beam }}} Q=\sum_{j=1}\left(f_{j}^{*} Z_{j} \varepsilon_{j}\right)
\end{gathered}
$$

Power from recycled electrons in excess of $P_{\min }$ is lost by Joule heating to inelastic plasma processes and heating of the electrode and channel walls. This loss may be estimated using Eq. (23), and places an upper limit on the applied discharge power not applied to ionization or beam kinetic energy:

$$
P_{\text {loss }}=P_{d}-P_{\text {jet }}-P_{\text {min }}
$$

A more conventional metric of energy loss is the total effective ionization cost per beam ion. This parameter was described for ion thrusters for a singly charged beam [48]. In Eq. (24), the equation has been adapted for Hall thrusters based on Eqs. (21) and (22) to account for multiply charged ions and the loss of ion acceleration voltage. Expressing the effective ionization cost per beam ion in terms of utilization efficiencies indicates this parameter may increase during high-discharge voltage $V_{d}$ Hall thruster operation:

$$
\varepsilon_{B}=\frac{\left(P_{d}-P_{\mathrm{jet}}\right)}{I_{\text {Beam }}} Q=V_{d} Q\left[\frac{1}{(1-r)}-(1-\beta)\right]
$$

\section{Evaluating Plume Divergence Losses in Beam Efficiency}

The momentum-weighted average plume divergence is defined in Eq. (25) as the measured thrust component directed along the thruster centerline relative to the theoretical thrust achieved when all ions are traveling parallel to thruster centerline. Momentum losses associated with plume divergence may be calculated with knowledge of the input mass flow, measured thrust, and the mass-weighted average velocity:

$$
\Psi_{B}=\langle\cos (\theta)\rangle_{m v}^{2}=\left(\frac{T}{\dot{m}_{T}\langle\bar{v}\rangle_{m}}\right)^{2}
$$

The value $\langle\cos (\theta)\rangle^{2}$ has been used in previous analyses to describe plume focusing [27], but there has not been a consistent method to calculate the effect of plume momentum divergence on thrust. This is primarily due to the difficulty of measuring particle velocity throughout the plume. Charge divergence in the plume is indicative of off-axis velocity losses in thrust and is a useful alternative for experimental characterization of performance losses due to plume divergence. The momentum-weighted average divergence is approximated as the charge-weighted average divergence in Eq. (26) for an axisymmetric plume, which enables calculation of off-axis cosine losses in Eq. (27) using the ratio of the axial component of beam current $I_{\text {Axial }}$ relative to total beam current as measured by a Faraday probe:

$$
\begin{gathered}
\langle\cos (\theta)\rangle_{m v}^{2}=\left(\frac{2 \pi R^{2} \int_{0}^{\pi / 2}[\dot{m}(\theta) \bar{v}(\theta) / J(\theta)] J(\theta) \cos (\theta) \sin (\theta) \mathrm{d} \theta}{2 \pi R^{2} \int_{0}^{\pi / 2}[\dot{m}(\theta) \bar{v}(\theta) / J(\theta)] J(\theta) \sin (\theta) \mathrm{d} \theta}\right)^{2} \\
\cong\left(\frac{2 \pi R^{2} \int_{0}^{\pi / 2} J(\theta) \cos (\theta) \sin (\theta) \mathrm{d} \theta}{2 \pi R^{2} \int_{0}^{\pi / 2} J(\theta) \sin (\theta) \mathrm{d} \theta}\right)^{2}=\langle\cos (\theta)\rangle_{J}^{2} \\
\Psi_{B} \cong\langle\cos (\theta)\rangle_{J}^{2}=\left(\frac{I_{\text {Axial }}}{I_{\text {Beam }}}\right)^{2}
\end{gathered}
$$

Characterization of off-axis cosine losses in Eq. (26) quantifies the axial component of the ion beam that generates thrust. This formulation has been used in past analyses $[25,49]$ and creates a method where the plume divergence vector loss is evaluated in a scalar form. The calculation of $\Psi_{B}$ is complicated by the presence of charge exchange (CEX) in the plume, which increases measured beam current at large angles from the centerline and artificially increases divergence losses.

An effective plume divergence angle $\lambda$ may be calculated as shown in Eq. (28). This angle is significantly less than the typically reported 95\% divergence half-angle:

$$
\lambda=\cos ^{-1}\left(\langle\cos (\theta)\rangle_{J}\right)=\cos ^{-1}\left(\frac{I_{\text {Axial }}}{I_{\text {Beam }}}\right)
$$

The ratio $\dot{m}(\theta) v(\theta) / J(\theta)$ introduced in Eq. (26) reveals the difference between momentum-weighted divergence and chargeweighted divergence. This ratio is evaluated in Appendix $\mathrm{C}$ for variations in mass utilization and ion species population. In Eq. (29), the ratio is evaluated at angular position $\theta$ and reduced to a function of average ion charge:

$$
\frac{\dot{m}(\theta) \bar{v}(\theta)}{J(\theta)}=\left.\left(2 V_{d} \frac{\mathcal{M}}{\mathcal{F}}\right)\left(\frac{\Phi_{P}}{\chi}\right)^{1 / 2}\left[1+\frac{y_{0}^{2}\left(1-\Phi_{m}\right)}{\chi}\right]^{1 / 2}\right|_{\theta} \propto Q^{-1 / 2}
$$

Spatial variation of the average ion charge in the plume is the primary source of discrepancy between momentum-weighted divergence and charge-weighted divergence. Significant variations in $Q$ within the angular region of highest beam current will have the greatest effect on plume divergence calculations. Although experimental measurements have shown the current fractions of higher charge states are often increased away from the Hall thruster centerline axis, the angular variations in Eq. (29) are not large enough to affect the ratio in Eq. (26). Variations in propellant efficiency, mass utilization, and average ion acceleration potential in the plume may also result in disparities, but are secondary effects and not expected to fluctuate at the angular region of peak beam current.

\section{E. Evaluating Exchange Parameters and Thruster Performance}

Two experimental parameters, denoted $E_{1}$ and $E_{2}$, may be written using the preceding utilization efficiencies to isolate changes in performance due to processes related to thrust or discharge current. The parameters are formed in Eq. (30) such that the product of $E_{1}$ and $E_{2}$ is equal to the total thruster efficiency. Equations (31) and (32) show how these quantities are calculated based solely on telemetry and thrust measurements and provide insight about the relative magnitudes of the individual utilization efficiencies in the absence of plume measurements:

$$
\begin{gathered}
\eta_{T}=\left[\begin{array}{ll}
\Phi_{P} & \Psi_{B}(1-\beta) \chi
\end{array}\right]\left[\frac{(1-r)}{\chi}\right]=E_{1} E_{2} \\
E_{1}=\Phi_{P} \Psi_{B}(1-\beta) \chi=\frac{\frac{1}{2}\left[T / \dot{m}_{T}\right]^{2}}{V_{d}(\mathcal{F} / \mathcal{M})} \\
E_{2}=\frac{(1-r)}{\chi}=\frac{\dot{m}_{T}}{I_{d}} \frac{\mathcal{F}}{\mathcal{M}}
\end{gathered}
$$

For fixed thruster telemetry inputs $V_{d}$ and $\dot{m}_{T}$, the dimensionless experimental parameter $E_{1}$ separates changes in thruster efficiency directly to variations in thrust, and $E_{2}$ isolates changes due to variations in discharge current. The quantity $E_{1} \sim T^{2}$ and is a function of propellant efficiency, beam efficiency, voltage utilization, and $\chi$. Experimental parameter $E_{1}$ relates the applied acceleration potential to dispersion and divergence of the jet. The quantity $E_{2} \sim I_{d}^{-1}$ and is a function of current utilization and $\chi$. Experimental parameter $E_{2}$ relates the input flow of mass to the total output flow of charge. The inverse of $E_{2}$ was used in the Soviet literature [50] as early as 1978 and termed the exchange parameter $[51,52]$. The naming convention adopted here describes the exchange of applied input parameters to operational thruster properties. Thus, $E_{1}$ is termed the voltage 
exchange parameter and $E_{2}$ is termed the mass exchange parameter. Although ionization and acceleration processes are closely coupled, the form of the experimental parameters indicates that propellant efficiency, beam efficiency, and voltage utilization are principal in the formation of directed thrust. In the absence of diagnostics for the determination of plasma properties, these experimental parameter groups allow limits to be placed on acceptable values for the average charge, mass utilization, and plume divergence $[53,54]$.

The loss mechanisms that effect $T / P$ and total $I_{\text {sp }}$ are shown in Eqs. (33) and (34) in terms of the experimental parameters $E_{1}$ and $E_{2}$ and in terms of the utilization efficiencies. These formulations indicate that low current utilization and large $Q$ will decrease $T / P$. Conversely, specific impulse is not directly affected by current utilization and increases for high-mass utilization and large $Q$ :

$$
\begin{aligned}
\frac{T}{P_{d}} & =E_{2} E_{1}^{1 / 2}\left(\frac{2}{V_{d}} \frac{\mathcal{M}}{\mathcal{F}}\right)^{1 / 2} \\
& =(1-r)(1-\beta)^{1 / 2}\left(\frac{\Phi_{P} \Psi_{B}}{\chi}\right)^{1 / 2}\left(\frac{2}{V_{d}} \frac{\mathcal{M}}{\mathcal{F}}\right)^{1 / 2} \\
I_{\text {sp }} g & =E_{1}^{1 / 2}\left(2 V_{d} \frac{\mathcal{F}}{\mathcal{M}}\right)^{1 / 2}=(1-\beta)^{1 / 2}\left(\chi \Phi_{P} \Psi_{B}\right)^{1 / 2}\left(2 V_{d} \frac{\mathcal{F}}{\mathcal{M}}\right)^{1 / 2}
\end{aligned}
$$

The $T / P$ formulation is similar to the one-dimensional analysis used to estimate thrust of the SERT-II ion thrusters, which is equivalent to Eq. (33) when the term $\left(\Phi_{P} \Psi_{B} / \chi\right)$ is unity [55-60]. An analogous expression was used to estimate thrust of the NSTAR ion thrusters onboard NASA's Deep Space 1 by including factors to estimate the effect of multiply charged ions and beam cosine losses [61]. These factors were similar those in the formulation of thrust by Masek et al. and are related to the ratio $\left(\Phi_{P} \Psi_{B} / \chi\right)^{1 / 2}$ for a bimodal ion population [18]. The formulations of $T / P$ and $I_{\text {sp }}$ in Eqs. (33) and (34) will be used in addition to the total efficiency to evaluate the fidelity of plume measurements in characterizing thruster performance.

\section{Case Study of Low-Discharge Voltage Operation}

\section{A. Experimental Apparatus}

A case study of low-discharge voltage operation of a laboratory model magnetic layer Hall thruster is presented to illustrate the potential for enhanced understanding of loss mechanisms with an array of diagnostics. The investigation of a nominal $6 \mathrm{~kW}$ thruster for 120,150 , and $300 \mathrm{~V}$ operation at 10 and $20 \mathrm{mg} / \mathrm{s}$ was conducted in chamber 3 at the U.S. Air Force Research Laboratory [2]. Beam neutralization is achieved with a centrally mounted $\mathrm{LaB}_{6}$ cathode, where the cathode flow fraction $(\mathrm{CFF}=$ cathode flow rate/anode flow rate) was maintained at $7 \%$ of the anode flow rate.

The study consisted of thrust measurements with an inverted pendulum thrust stand and examination of the ion voltage distribution, plasma potential, ion species composition, and ion current density in the far-field plume. Facility effects on thrust and discharge current were characterized by extrapolating measurements at four background pressures to zero pressure.

Using a similar approach, nude Faraday probe current density measurements at each angular location in the plume were extrapolated to zero pressure. Nude Faraday probe sweeps were executed in a $1 \mathrm{~m}$ hemispherical arc from 0 to $180 \mathrm{deg}$. Corrections were applied to the current density profiles that account for ions collected in the gap between the collector and guard ring, CEX collisions and neutral ingestion resulting from facility effects, and systematic error caused by measuring the current density profiles of an annular device as a point source [2]. The beam currents calculated with these farfield measurements were consistent with near-field measurements of this thruster model at the University of Michigan for the 150 and $300 \mathrm{~V}$ conditions [62]. Improvements in the analysis of far-field Faraday probe current density measurements have reduced the uncertainty in ion beam current to $\pm 6 \%$ and the error in axial beam current to approximately to $\pm 10 \%$ [2].

RPA measurements were taken at several angular positions in a $1 \mathrm{~m}$ hemispherical arc, and the most probable ion pass voltage was corrected with Langmuir probe plasma potential measurements located less than $3 \mathrm{~cm}$ away. The resulting most probable ion acceleration potential showed negligible variation over a large angular span and was not expected to vary with facility effects. During low-voltage operation, dispersion of the RPA ion voltage distribution increased. The uncertainty in average ion acceleration potential is estimated as $\pm 25 \%$ of the half-width at half-maximum of the RPA trace in addition to $25 \%$ uncertainty in the plasma potential.

The ion species composition was evaluated from 1.0 to $1.3 \mathrm{~m}$ downstream of the exit plane on channel centerline and exhibited minimal variation in the ion distribution. Species current fractions were corrected for the attenuation of beam ions due to CEX collisions using the procedure outlined by Shastry et al. [63]. Conclusions from a recent study of angularly resolved ExB probe spectra using this thruster model asserted that a measurement on channel centerline was representative of the species fractions throughout the plume and deviated from plume averaged results by less than $1.5 \%$ over a wide range of thruster operating conditions [64]. In this case study, ExB and RPA results are from channel centerline measurements, and variations in the plume are accounted for in the specified uncertainty.

The primary uncertainties in this analysis are in the axial component of ion beam current from Faraday probe measurements and dispersion of the RPA ion voltage distribution during low-discharge voltage operation. Relationships for the propagation of uncertainty in the utilization efficiencies and performance parameters are listed in Appendix D, and are based on the International Organization for Standardization Guide to the Expression of Uncertainty in Measurement [65]. Further details concerning the investigation, facility, diagnostics, and measurement uncertainty are described elsewhere [2].

In the following section, the voltage utilization, current utilization, and charge utilization will be equivalent to past methodologies. However, there are several key differences. One difference is the increased accuracy of Faraday probe measurements used in this study, which enables a more accurate calculation of the current utilization. Determination of the beam current and recycled electron flow is critical for a reliable evaluation of performance parameters determined with far-field plasma properties. A second difference with past methodologies is the inclusion of cathode flow rate in mass utilization, which will capture the performance benefits of increased cathode propellant and assess effects due to ionized cathode flow in the thruster discharge. The minimal effect of neutral propellant will be characterized in neutral-gain utilization. A final difference with many past methodologies is characterizing the effect of plume divergence on total efficiency with the ratio of the axial component of ion beam current relative to the total ion beam current. This value will be compared to the commonly reported $95 \%$ divergence half-angle. These differences will be emphasized in the following section.

\section{B. Experimental Results}

Experimental results and measurement uncertainty are listed in Table 1 for 10 and $20 \mathrm{mg} / \mathrm{s}$ anode flow operation from 120 to $300 \mathrm{~V}$ discharge. This set of thrust and plume measurements enable full characterization of the thruster utilization efficiencies and performance parameters. The speed of neutral propellant is estimated at $v_{0}=300 \mathrm{~m} / \mathrm{s}$ from previous laser-induced fluorescence measurements of this thruster operating over a range of discharge voltages and anode mass flow rates [44].

Total thruster efficiency, total $I_{\mathrm{sp}}$, and $T / P$ based on plume measurements are compared to the values determined by thrust measurements in Fig. 1. Agreement between the performance parameters is within the error bars for all operating conditions. The consistent agreement between thrust measurements and plume measurements indicates the efficiency architecture is accurately capturing the thruster performance characteristics. A sensitivity analysis of measured parameters on performance suggests the deviations are caused 
Table 1 Thrust, telemetry, and far-field plume measurements of a $6 \mathrm{~kW}$ laboratory Hall thruster [2]

\begin{tabular}{lcccccc}
\hline \hline & \multicolumn{3}{c}{$10 \mathrm{mg} / \mathrm{s}$ anode flow rate } & \multicolumn{3}{c}{$20 \mathrm{mg} / \mathrm{s}$ anode flow rate } \\
\cline { 2 - 7 } & $120 \mathrm{~V}$ & $150 \mathrm{~V}$ & $300 \mathrm{~V}$ & $120 \mathrm{~V}$ & $150 \mathrm{~V}$ & $300 \mathrm{~V}$ \\
\hline$V_{d}, \mathrm{~V}$ & $120 \pm 0.05 \%$ & $150 \pm 0.05 \%$ & $300 \pm 0.05 \%$ & $120 \pm 0.05 \%$ & $150 \pm 0.05 \%$ & $300 \pm 0.05 \%$ \\
$I_{d}, \mathrm{~A}$ & $9.6 \pm 0.2 \%$ & $9.3 \pm 0.2 \%$ & $8.8 \pm 0.2 \%$ & $21.6 \pm 0.2 \%$ & $21.5 \pm 0.2 \%$ & $20.6 \pm 0.2 \%$ \\
$\dot{m}_{T}, \mathrm{mg} / \mathrm{s}$ & $10.9 \pm 1 \%$ & $10.9 \pm 1 \%$ & $10.9 \pm 1 \%$ & $21.4 \pm 1 \%$ & $21.4 \pm 1 \%$ & $21.4 \pm 1 \%$ \\
$T, \mathrm{mN}$ & $96 \pm 1 \%$ & $116 \pm 1 \%$ & $189 \pm 1 \%$ & $218 \pm 1 \%$ & $263 \pm 1 \%$ & $410 \pm 1 \%$ \\
$\Omega_{1}$ & $0.96 \pm 0.04$ & $0.91 \pm 0.04$ & $0.90 \pm 0.04$ & $0.87 \pm 0.03$ & $0.84 \pm 0.04$ & $0.78 \pm 0.03$ \\
$\Omega_{2}$ & $0.04 \pm 0.01$ & $0.08 \pm 0.02$ & $0.07 \pm 0.02$ & $0.13 \pm 0.03$ & $0.16 \pm 0.03$ & $0.16 \pm 0.03$ \\
$\Omega_{3}$ & $0.00 \pm 0.00$ & $0.01 \pm 0.01$ & $0.03 \pm 0.02$ & $0.00 \pm 0.00$ & $0.00 \pm 0.00$ & $0.06 \pm 0.03$ \\
$V_{a}, \mathrm{~V}$ & $92 \pm 8$ & $120 \pm 7$ & $266 \pm 7$ & $95 \pm 7$ & $124 \pm 9$ & $268 \pm 9$ \\
$I_{\text {Beam }}, \mathrm{A}$ & $6.8 \pm 6 \%$ & $6.9 \pm 6 \%$ & $7.5 \pm 6 \%$ & $15.8 \pm 6 \%$ & $15.5 \pm 6 \%$ & $16.4 \pm 6 \%$ \\
$I_{\text {Axial }}, \mathrm{A}$ & $5.7 \pm 10 \%$ & $6.3 \pm 10 \%$ & $7.2 \pm 10 \%$ & $14.0 \pm 10 \%$ & $14.4 \pm 10 \%$ & $15.8 \pm 10 \%$ \\
$\lambda=\mathrm{cos}^{-1}, \Phi_{B}^{1 / 2}$ & $33 \pm 2 \mathrm{deg}$ & $24 \pm 3 \mathrm{deg}$ & $15 \pm 4 \mathrm{deg}$ & $27 \pm 2 \mathrm{deg}$ & $22 \pm 3 \mathrm{deg}$ & $16 \pm 4 \mathrm{deg}$ \\
$95 \%$ half-angle & $69 \mathrm{deg}$ & $63 \mathrm{deg}$ & $53 \mathrm{deg}$ & $71 \mathrm{deg}$ & $67 \mathrm{deg}$ & $58 \mathrm{deg}$ \\
$v_{0}, \mathrm{~m} / \mathrm{s}$ & $300 \pm 50 \%$ & $300 \pm 50 \%$ & $300 \pm 50 \%$ & $300 \pm 50 \%$ & $300 \pm 50 \%$ & $300 \pm 50 \%$ \\
\hline \hline
\end{tabular}

by underprediction of the axial component of ion beam current [2]. For the $120-\mathrm{V}, 10-\mathrm{mg} / \mathrm{s}$ case where the difference is largest, increasing the axial component of ion beam current from 5.7 to $6.0 \mathrm{~A}$ results in equivalent performance characteristics between the thrust and plume measurements. The axial component of ion beam current is only used for calculation of beam efficiency and divergence, and the large uncertainty will not affect trends of other utilization efficiencies.

In Fig. 2, total thruster efficiency is separated into utilization efficiencies. Decreased efficiency at low-discharge voltage is primarily due to increased beam divergence and increased energy losses. Variations in beam efficiency with discharge voltage will be discussed first, followed by propellant efficiency and energy efficiency.

Reducing discharge voltage from 300 to $120 \mathrm{~V}$ resulted in decreased beam efficiency by approximately 0.15 and 0.22 for 10 and $20 \mathrm{mg} / \mathrm{s}$ anode flow rate, respectively. This corresponds to a large increase in the plume divergence half-angle from 16 to $33 \mathrm{deg}$ at $10 \mathrm{mg} / \mathrm{s}$ and 16 to $28 \mathrm{deg}$ at $20 \mathrm{mg} / \mathrm{s}$. If the axial component of ion beam current is underpredicted in the $120-\mathrm{V}, 10-\mathrm{mg} / \mathrm{s}$ case, the "corrected" value of $6.0 \mathrm{~A}$ also results in a plume divergence halfangle of $28 \mathrm{deg}$. In all cases, the $95 \%$ divergence half-angle is more than double $\lambda$. This large difference underscores the high degree of collimation in state-of-the-art Hall thrusters, and is a more accurate metric of cosine losses in thrust.

In both the 10 and $20 \mathrm{mg} / \mathrm{s}$ cases, propellant efficiency exhibited a slight increase at the lowest discharge voltages. This effect is studied

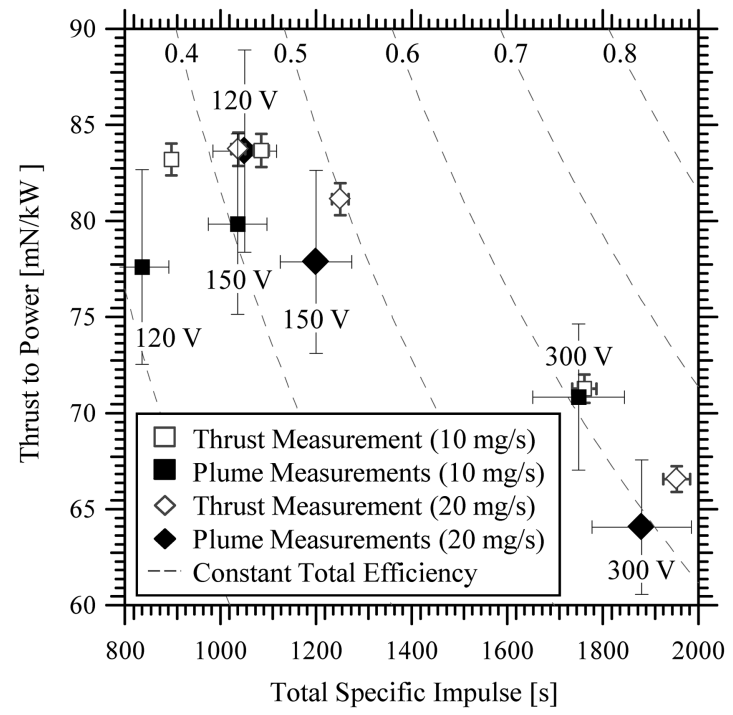

Fig. 1 Thrust to power ratio as a function of total specific impulse with lines of constant total efficiency for a $6 \mathrm{~kW}$ laboratory Hall thruster ranging from 120 to $300 \mathrm{~V}$ at $10-20 \mathrm{mg} / \mathrm{s}$ anode flow and $7 \% \mathrm{CFF}$ operation. by decomposing propellant efficiency into mass utilization, charge utilization, and neutral-gain utilization efficiencies in Fig. 3 . The charge utilization decreased at higher discharge voltages due to the production of multiply charged ions, which is consistent with past investigations $[40,66]$. Increased propellant efficiency due to the neutral-gain utilization was approximately $1 \%$ and had minimal effect on the overall performance. Mass utilization increased from 150 to $120 \mathrm{~V}$ discharge, which is contrary to previous analytical estimates of low-voltage operation [67]. Increased mass utilization may be caused by increased ion beam current and/or decreased

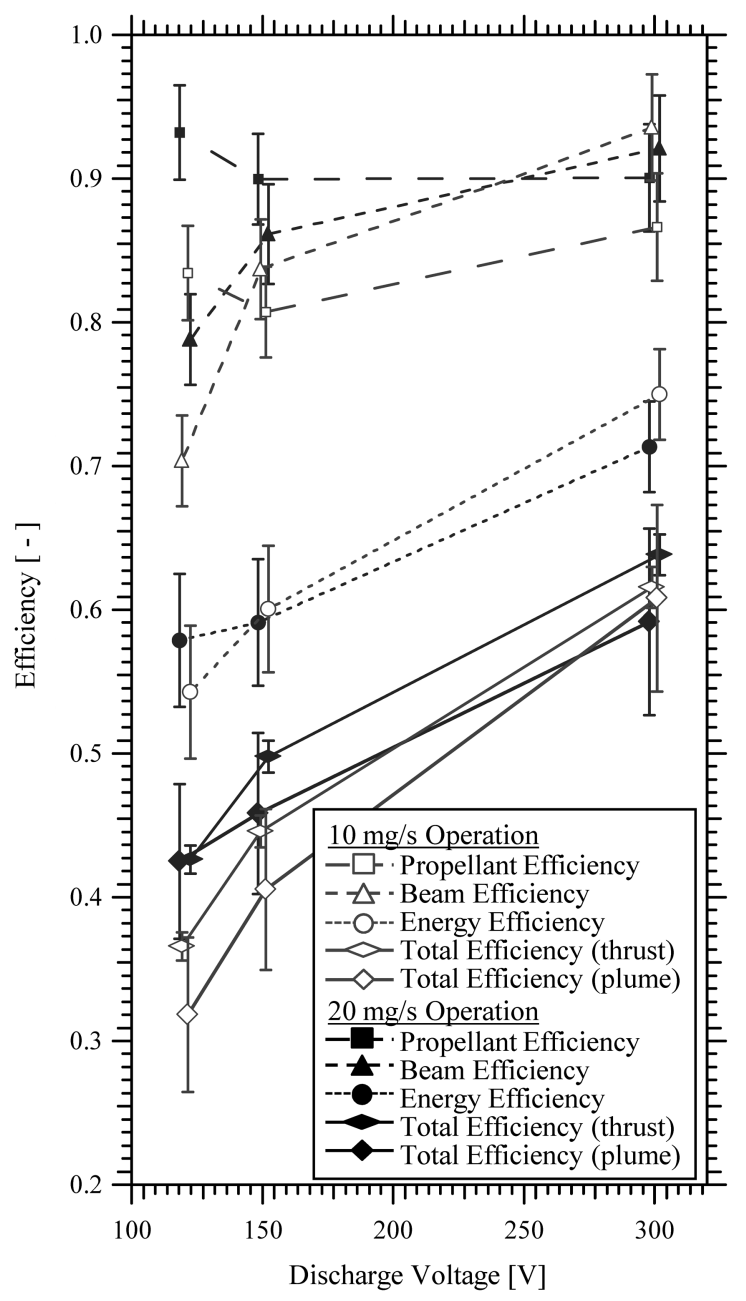

Fig. 2 Total thruster efficiency and utilization efficiencies as a function of discharge voltage for a $6 \mathrm{~kW}$ laboratory Hall thruster ranging from 120 to $300 \mathrm{~V}$ at $10-20 \mathrm{mg} / \mathrm{s}$ anode flow and $7 \%$ CFF operation. 


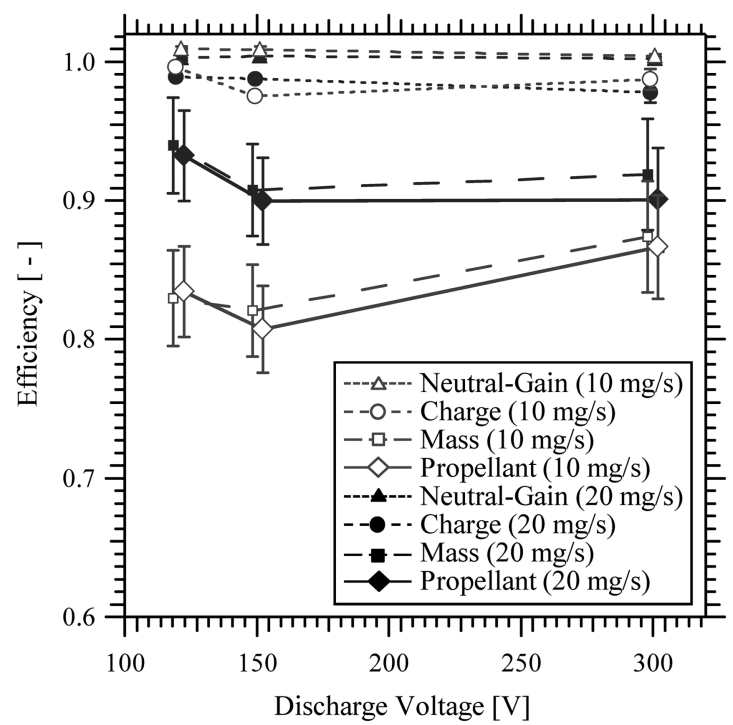

Fig. 3 Propellant efficiency, mass utilization, charge utilization, and neutral-gain utilization as a function of discharge voltage for a $6 \mathrm{~kW}$ laboratory Hall thruster ranging from 120 to $300 \mathrm{~V}$ at $10-20 \mathrm{mg} / \mathrm{s}$ anode flow and 7\% CFF operation. Error bars of neutral-gain utilization and charge utilization are within the markers.

average ion charge. The rise in mass utilization at $120 \mathrm{~V}, 10 \mathrm{mg} / \mathrm{s}$ is due to a reduction in average ion charge, which is evident by the increase in $\mathrm{Xe}^{+1}$ current fraction and corresponding increase in charge utilization. Not accounting for the cathode flow fraction resulted in mass utilization greater than unity for low-discharge voltage conditions, which signifies ionization of the cathode flow. Ionized cathode flow may augment ion beam current and cause increased mass utilization at $120 \mathrm{~V}$ discharge, as evidenced by the increase to $\Phi_{m}=1.01$ for both the 10 and $20 \mathrm{mg} / \mathrm{s}$ conditions.

Losses in energy efficiency are studied in terms of current utilization and voltage utilization in Fig. 4. At low voltage, the minimum ionization potential becomes a larger faction of the applied anode potential. The decrease in voltage utilization is approximately equal to the fractional increase of the xenon ionization potential relative to the thruster discharge voltage $\left(\sim 12 \mathrm{eV} / V_{d}\right)$. Current utilization and the fraction of electron current to the anode is the dominant loss mechanism in energy efficiency. In general, the fraction of electron current to the anode increased as discharge voltage decreased. The exception occurred for the 120-V, 20-mg/s operation, where current utilization increased due to a $1.1 \mathrm{~A}$ increase in

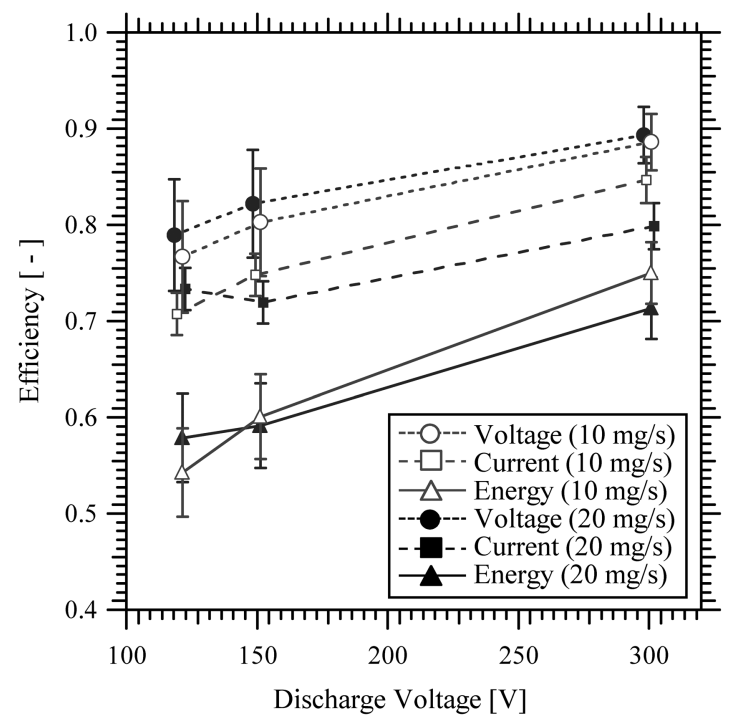

Fig. 4 Energy efficiency, voltage utilization, and current utilization as a function of discharge voltage for a $6 \mathrm{~kW}$ laboratory Hall thruster ranging from 120 to $300 \mathrm{~V}$ at $10-20 \mathrm{mg} / \mathrm{s}$ anode flow and $7 \%$ CFF operation. beam ion current. This improvement is consistent with the increase in mass utilization.

To more accurately study this phenomenon at $120 \mathrm{~V}$, the cathode flow fraction was increased to $12 \%$ CFF for $10 \mathrm{mg} / \mathrm{s}$ anode flow operation and $16 \% \mathrm{CFF}$ for $20 \mathrm{mg} / \mathrm{s}$ anode flow rate operation. These points were chosen to maintain total thruster efficiency for a decrease in total $I_{\mathrm{sp}}$ and an increase in the $T / P$ ratio. Table 2 lists the relevant operating characteristics and utilization efficiencies. Increasing the CFF increased beam efficiency at the expense of decreased mass utilization. Decreased plume divergence is typically associated with an upstream shift in the primary ion acceleration zone. This is supported by the increased average ion charge of the higher CFF cases. The implications for low-discharge voltage propellant ionization and acceleration will be discussed in the next section.

\section{Discussion of Performance Loss Mechanisms}

Energy efficiency was characterized as a loss in 1) acceleration potential and 2) anode electron current in Fig. 4. These values of voltage and current utilization are combined with the species current fractions to calculate power losses and the effective ionization cost in Fig. 5. The minimum power loss increased with anode mass flow rate and gradually increased with discharge voltage. Beam power losses, calculated with Eq. (23), increased with discharge power and discharge voltage, which is expected with the decrease in energy efficiency. The $P_{\text {loss }}$ term characterizes the maximum power not applied to propellant ionization or jet kinetic energy that is lost to ohmic heating, excitation, and radiation. Comparison of the $2.5 \mathrm{~kW}$ operating conditions $(120-\mathrm{V}, 20-\mathrm{mg} / \mathrm{s}$ anode flow vs $300-\mathrm{V}$, $10-\mathrm{mg} / \mathrm{s}$ anode flow) shows that the power losses are nearly double for the $120 \mathrm{~V}$ discharge and can be attributed to decreased current utilization and voltage utilization. However, the effective ionization cost at $120 \mathrm{~V}$ is $20 \mathrm{eV}$ /ion less than the $300 \mathrm{~V}$ conditions due to the increased ion beam current exiting the discharge. Thus, for comparison of constant power operation, a larger fraction of the discharge energy is applied to accelerate fewer ions to high exhaust velocity during high-voltage operation. High discharge voltage operation is associated with increased ionization cost per beam ion due to the production of multiply charged ions, excitation, and high-energy wall collisions. Conversely, during low-voltage operation, a larger fraction of the discharge energy is applied to ionization of propellant with fewer Joule heating losses. Therefore, it may be concluded that the energy per beam ion lost to ohmic heating, excitation, radiation, and other forms of Joule heating are reduced for this low-discharge voltage operating condition.

Experimental studies of the energy production cost per plasma ion in ion thrusters concluded the primary losses were inelastic collisional inefficiencies and electron energy transport to the anode [68]. A lower limit on the ionization cost was estimated at $60-80 \mathrm{eV}$ per beam ion based on the wall losses associated with the minimum electron temperature required to sustain ionization. Brophy [69] further advanced the understanding of ionization processes in ion thrusters and found the ion thruster behavior changed during lowdischarge voltage operation. As the applied anode potential was decreased, the average energy of Maxwellian electrons showed large variations with propellant flow rate. The mechanism for decreased electron temperature was attributed to the direct thermalization of primary electrons as the result of Maxwellian-primary electron collisions, because the collision cross section between these populations increases with decreasing primary electron temperature.

Several studies of the Hall thruster discharge have shown electron temperature increases linearly with anode potential and saturates during very high-voltage operation [70-72]. This linear regime $\left(V_{d}<400 \mathrm{~V}\right)$ is consistent with minimal near-wall sheath effects and negligible secondary electron emission effects. If the linear experimental trend of electron temperature with discharge voltage in the study by Raitses et al. [71] is extrapolated to $\sim 120 \mathrm{~V}$, the maximum electron temperature will be approximately equal to the first ionization potential of xenon $(\sim 12 \mathrm{eV})$. Measurements of internal plasma properties in a low-voltage Hall thruster discharge $(<150 \mathrm{~V})$ 
Table 2 Performance comparison for increased cathode flow fraction operation at $120 \mathrm{~V}$ [2]

\begin{tabular}{lcccc}
\hline \hline & \multicolumn{2}{c}{$10 \mathrm{mg} / \mathrm{s}$ anode flow rate } & \multicolumn{2}{c}{$20 \mathrm{mg} / \mathrm{s}$ anode flow rate } \\
\cline { 2 - 5 } & $120 \mathrm{~V}, 7 \% \mathrm{CFF}$ & $120 \mathrm{~V}, 12 \% \mathrm{CFF}$ & $120 \mathrm{~V}, \mathbf{7} \% \mathrm{CFF}$ & $120 \mathrm{~V}, 16 \% \mathrm{CFF}$ \\
\hline$V_{d}, \mathrm{~V}$ & $120 \pm 0.05 \%$ & $120 \pm 0.05 \%$ & $120 \pm 0.05 \%$ & $120 \pm 0.05 \%$ \\
$I_{d}, \mathrm{~A}$ & $9.6 \pm 0.2 \%$ & $9.5 \pm 0.2 \%$ & $21.6 \pm 0.2 \%$ & $22.6 \pm 0.2 \%$ \\
$\dot{m},, \mathrm{mg} / \mathrm{s}$ & $10.9 \pm 1 \%$ & $11.4 \pm 1 \%$ & $21.4 \pm 1 \%$ & $23.2 \pm 1 \%$ \\
$T, \mathrm{mN}$ & $96 \pm 1 \%$ & $98 \pm 1 \%$ & $218 \pm 1 \%$ & $234 \pm 1 \%$ \\
$I_{\text {Beam }}, \mathrm{A}$ & $6.8 \pm 6 \%$ & $6.8 \pm 6 \%$ & $15.8 \pm 6 \%$ & $16.6 \pm 6 \%$ \\
$Q$ & $1.02 \pm 0.02$ & $1.05 \pm 0.02$ & $1.07 \pm 0.02$ & $1.09 \pm 0.02$ \\
Voltage utilization & $0.77 \pm 0.06$ & $0.77 \pm 0.06$ & $0.79 \pm 0.06$ & $0.80 \pm 0.07$ \\
Current utilization & $0.71 \pm 0.02$ & $0.71 \pm 0.02$ & $0.73 \pm 0.02$ & $0.74 \pm 0.02$ \\
Mass utilization & $\mathbf{0 . 8 3} \pm \mathbf{0 . 0 3}$ & $\mathbf{0 . 7 7} \pm \mathbf{0 . 0 3}$ & $\mathbf{0 . 9 4} \pm \mathbf{0 . 0 4}$ & $\mathbf{0 . 9 0} \pm \mathbf{0 . 0 3}$ \\
Charge utilization & $0.99 \pm 0.01$ & $0.99 \pm 0.01$ & $0.99 \pm 0.01$ & $0.99 \pm 0.01$ \\
Neutral-gain utilization & $1.01 \pm 0.01$ & $1.01 \pm 0.01$ & $1.00 \pm 0.01$ & $1.00 \pm 0.01$ \\
Beam efficiency & $0.70 \pm 0.03$ & $0.77 \pm 0.03$ & $0.79 \pm 0.03$ & $0.82 \pm 0.03$ \\
Divergence half-angle & $\mathbf{3 3} \pm \mathbf{2 ~ d e g}$ & $\mathbf{2 9} \pm \mathbf{2 ~ d e g}$ & $\mathbf{2 7} \pm \mathbf{2 ~ d e g}$ & $\mathbf{2 5} \pm \mathbf{2 ~ d e g}$ \\
\hline \hline
\end{tabular}

are limited, but the results presented here provide limited insight into the nature of very low-voltage discharge properties. The experimental results in this study support the concept that low-voltage operation corresponds to a decrease in energy losses per beam ion caused by inelastic collisions and high-energy wall collisions. These trends are consistent with the increased mass utilization at $120 \mathrm{~V}$ compared to $150 \mathrm{~V}$. A corollary effect of low-discharge voltage operation is the downstream shift in ion acceleration, which reduces the wall surface area exposed to high-energy particle collisions and minimizes ohmic heating losses at the expense of increased radial ion acceleration. This relationship is evident in Table 2, where increased cathode flow fraction corresponds to increased beam efficiency and decreased mass utilization for $120 \mathrm{~V}$ operation at 10 and $20 \mathrm{mg} / \mathrm{s}$ anode flow rate.

The case study presented here is intended to provide a framework for analysis of far-field plume measurements and demonstrate a

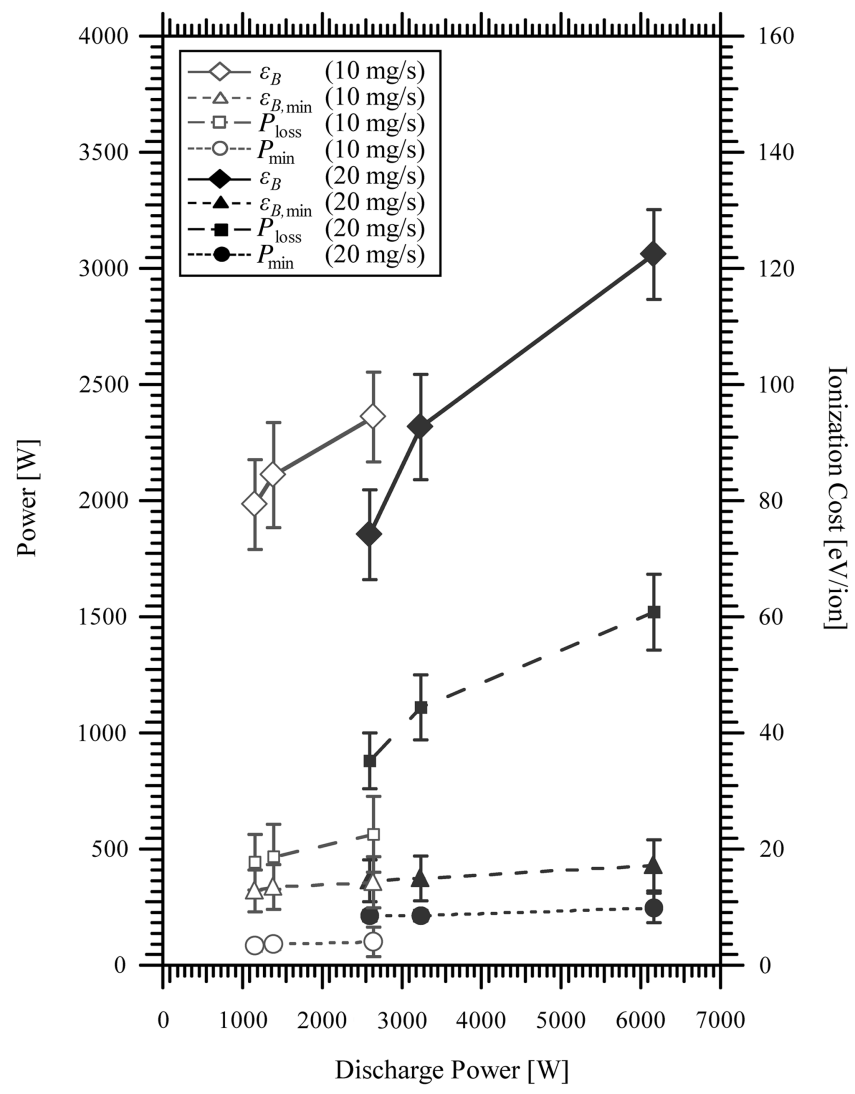

Fig. 5 Power losses and beam ionization cost as a function of discharge power for a $6 \mathrm{~kW}$ laboratory Hall thruster ranging from 120 to $300 \mathrm{~V}$ at 10-20 mg/s anode flow and 7\% CFF operation. qualitative comparison of plasma properties and trends with numerical simulations and internal plasma measurements. Insights related to propellant ionization and acceleration within the Hall thruster discharge were enhanced using the performance architecture in this paper. Nevertheless, the discussion of low-discharge voltage operation in this work is limited, and a more detailed investigation is necessary to study the relationships between plasma discharge physics with performance loss mechanisms.

\section{Conclusions}

Separation of axisymmetric, scalar thrust into mass-weighted and momentum-weighted terms enabled factorization of total thruster efficiency into the product of 1) energy efficiency, 2) propellant efficiency, and 3) beam efficiency. The analysis decomposed total efficiency from first principles and formulated the relationship such that losses associated with energy conversion were analyzed separately from losses associated with dispersion of the jet VDF and beam divergence. The momentum-weighted divergence loss term $\left[\langle\cos (\theta)\rangle_{m v}^{2}\right]$ contains all jet vector losses, and differences from the current-weighted divergence was characterized. The proposed analysis was compared to past performance methodologies, with similarities to previous architectures formulated by Masek et al. in the ion thruster community [18], Belan et al. from the Kharkov Aviation Institute [25], and a contemporary methodology by Hofer and Gallimore $[40, \overline{47}]$.

The effects of multiply charged ions were included in the analysis and the neutral-gain utilization was introduced to account for the effect of neutrals. Incorporation of the finite effect of neutral flow on thruster performance is not conventional, and the neutral-gain utilization is a new concept. Although it may be negligible in most instances, thrusters with a high fraction of thermalized neutral flow or poor propellant injection may experience performance benefits of several percent. Therefore, a rudimentary estimate of the exit exhaust velocity of neutral flow is recommended for future performance studies. Although the overall effect is expected to be minor, it provides a more accurate representation of Hall thruster performance characteristics for comparison over a wide range of discharge voltage and discharge power.

A case study was presented with experimental performance and far-field plume measurements for a $6 \mathrm{~kW}$ laboratory Hall thruster. Although the case study quantified a global voltage utilization and ion mass flow fractions based on a single measurement on channel centerline, more elaborate plume averaging techniques and incorporation of the ion energy distribution may be advantageous. Performance parameters calculated with plume diagnostics showed good agreement with performance based on thrust measurements. The performance methodology highlights low current utilization and large plume divergence as the primary loss mechanisms during lowvoltage operation. Increasing the cathode flow fraction increased the beam efficiency while decreasing mass utilization. Ionization cost and power losses of the global thruster discharge were compared with 
the minimum energy required for ionization. Decreased ionization cost at low-discharge voltage was attributed to reduced electron temperature, which is consistent with a reduction in ohmic heating and inelastic collisional losses on a per ion basis. A comparison of constant power operation indicated the low-voltage operating condition had a lower average ionization cost per beam ion despite the increase in total energy losses.

\section{Appendix A: Definitions of Mass-Weighted and Momentum-Weighted Quantities}

In Eq. (2), the steady-state equation for axisymmetric thrust directed along thruster centerline was factored into the product of total mass flow, mass-weighted average velocity, and momentumweighted average divergence using the definitions shown in Eqs. (A1-A4).

Hemispherical integration of mass flow rate throughout the plume at constant radius in Eq. (A1) is equal to the total mass flow rate supplied to the anode and cathode:

$$
\dot{m}_{T}=2 \pi R^{2} \int_{0}^{\pi / 2} \dot{m}(\theta) \sin (\theta) \mathrm{d} \theta
$$

The average velocity vector $\overline{\mathbf{v}}$ is defined in Eq. (A2) as the integral of the VDF over all velocity space for an axisymmetric plume at angular position $\theta$ and radius $R$. The radial propellant velocity component in spherical coordinates $\bar{v}$ is formulated in Eq. (A3), and the radial ion velocity component $\overline{v_{i}}$ is formulated in Eq. (A $\left.\overline{4}\right)$ using ion flow fractions for monoenergetic ion velocities. This outwardnormal velocity is the primary component of ions originating from the thruster discharge. Terms for squared radial ion velocity and squared radial propellant velocity are found using analogous expressions:

$$
\begin{gathered}
\overline{\mathbf{v}}=\iiint \mathbf{v} f(\mathbf{v}) \mathrm{d} \mathbf{v} / \iiint f(\mathbf{v}) \mathrm{d} \mathbf{v} \\
\bar{v}=\sum_{j=0} \frac{\dot{m}_{j}}{\dot{m}_{T}} v_{j}=\frac{\dot{m}_{i}}{\dot{m}_{T}} \sum_{j=0} f_{j}^{*} v_{j} \\
\bar{v}_{i}=\sum_{j=1} \frac{\dot{m}_{j}}{\dot{m}_{i}} v_{j}=\sum_{j=1} f_{j}^{*} v_{j}
\end{gathered}
$$

The mass-weighted average radial velocity component for an axisymmetric plume is defined in Eq. (A5) and simplified using Eq. (A1). The momentum-weighted average cosine is defined in Eq. ( $\overline{\mathrm{A} 6}$ ) and simplified using Eq. (A5). The definition of thrust in Eq. (2) is naturally produced through the relation of mass-weighted and momentum-weighted terms in Eq. (A6). This formulation of thrust sets the foundation for the Hall thruster efficiency architecture outlined in the paper:

$$
\begin{aligned}
& \langle\bar{v}\rangle_{m}=\frac{2 \pi R^{2} \int_{0}^{\pi / 2} \dot{m}(\theta) \bar{v}(\theta) \sin (\theta) \mathrm{d} \theta}{2 \pi R^{2} \int_{0}^{\pi / 2} \dot{m}(\theta) \sin (\theta) \mathrm{d} \theta} \\
& =\frac{2 \pi R^{2} \int_{0}^{\pi / 2} \dot{m}(\theta) \bar{v}(\theta) \sin (\theta) \mathrm{d} \theta}{\dot{m}_{T}} \\
& \langle\cos (\theta)\rangle_{m v}=\frac{2 \pi R^{2} \int_{0}^{\pi / 2} \dot{m}(\theta) \bar{v}(\theta) \cos (\theta) \sin (\theta) \mathrm{d} \theta}{2 \pi R^{2} \int_{0}^{\pi / 2} \dot{m}(\theta) \bar{v}(\theta) \sin (\theta) \mathrm{d} \theta} \\
& =\frac{2 \pi R^{2} \int_{0}^{\pi / 2} \dot{m}(\theta) \bar{v}(\theta) \cos (\theta) \sin (\theta) \mathrm{d} \theta}{\dot{m}_{T}\langle\bar{v}\rangle_{m}}
\end{aligned}
$$

All quantities are assumed steady state and evaluated at constant radius from the exit plane. For hemispherical integration about a point source, the measurement distance must be multiple thruster diameters downstream of the exit. The definitions in Eqs. (A1-A6) do not account for dispersion of the jet due to scattering and charge exchange ions in the plume. These processes will have a different effect depending on the diagnostic, facility, background pressure, and distance from the thruster. To this point, an axisymmetric spherical plume with outward-normal particle velocity and negligible facility effects are the only approximations required. Analytical techniques to evaluate global properties and account for facility effects, probe measurement uncertainty, and geometric variations associated with hemispherical measurement and integration about a point source will be dealt with separately.

\section{Appendix B: Formulation of Neutral-Gain Utilization in Propellant Efficiency}

Propellant efficiency characterizes dispersion of the VDF and is a measure of the jet momentum relative to the jet kinetic energy. In Eqs. (B1) and (B2), the second term in brackets in Eq. (7) is decomposed into the product of mass utilization and neutral-gain utilization:

$$
\begin{gathered}
\frac{\left[\langle\bar{v}\rangle_{m} /\left\langle\overline{v_{i}}\right\rangle_{m}\right]^{2}}{\left\langle\overline{v^{2}}\right\rangle_{m} /\left\langle\overline{v_{i}^{2}}\right\rangle_{m}}=\frac{\left[\sum_{j=0}\left[\left(\dot{m}_{j} / \dot{m}_{T}\right) v_{j}\right] / \sum_{j=1}\left[\left(\dot{m}_{j} / \dot{m}_{i}\right) v_{j}\right]\right]^{2}}{\sum_{j=0}\left[\left(\dot{m}_{j} / \dot{m}_{T}\right) v_{j}^{2}\right] / \sum_{j=1}\left[\left(\dot{m}_{j} / \dot{m}_{i}\right) v_{j}^{2}\right]} \\
=\frac{\left[\Phi_{m} \sum_{j=0}\left(f_{j}^{*} y_{j}\right) / \sum_{j=1}\left(f_{j}^{*} y_{j}\right)\right]^{2}}{\Phi_{m} \sum_{j=0}\left(f_{j}^{*} y_{j}^{2}\right) / \sum_{j=1}\left(f_{j}^{*} y_{j}^{2}\right)}
\end{gathered}
$$

$$
\begin{aligned}
& \frac{\left[\langle\bar{v}\rangle_{m} /\left\langle\overline{v_{i}}\right\rangle_{m}\right]^{2}}{\left\langle\overline{v^{2}}\right\rangle_{m} /\left\langle\overline{v_{i}^{2}}\right\rangle_{m}}=\Phi_{m} \frac{\left\{1+\left[y_{0}\left(1-\Phi_{m}\right) /\left(\Phi_{m} \sqrt{\Phi_{q} Q}\right)\right]\right\}^{2}}{1+\left[y_{0}^{2}\left(1-\Phi_{m}\right) /\left(\Phi_{m} Q\right)\right]} \\
& \quad=\Phi_{m} \Phi_{N-G}
\end{aligned}
$$

The neutral-gain utilization is defined in Eq. (B3), and is always greater than unity. The approximation in Eq. (12) is formulated by neglecting second-order terms with $y_{0}$ and shows $\Phi_{N-G}$ is primarily a function of the neutral speed and mass utilization. Effects that increase the neutral-gain utilization result in detrimental losses to other utilization efficiencies. Ideal thruster operation would correspond to unity neutral gain for $100 \%$ ionization or zero neutral speed for infinite neutral residence time in the channel:

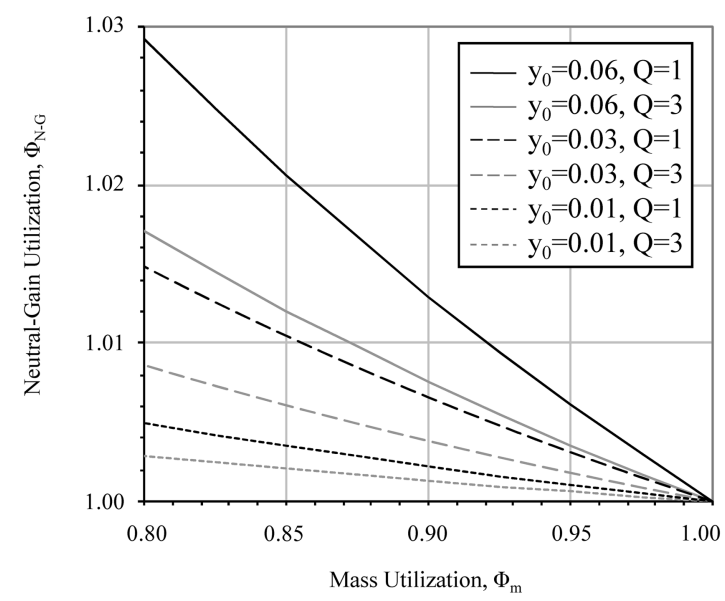

Fig. B1 Neutral-gain utilization as a function of mass utilization for $y_{0}=0.01,0.03$, and 0.06 . The range of neutral-gain utilization is bounded by lines of constant $Q=1$ and $Q=3$, which are limiting cases for a trimodal ion population. 


$$
\Phi_{N-G}=\frac{\left\{1+\left[y_{0}\left(1-\Phi_{m}\right) / \Phi_{m} \sqrt{\Phi_{q} Q}\right]\right\}^{2}}{\left\{1+\left[y_{0}^{2}\left(1-\Phi_{m}\right) / \Phi_{m} Q\right]\right\}} \approx 1+\frac{2 y_{0}\left(1-\Phi_{m}\right)}{\Phi_{m} \sqrt{\Phi_{q} Q}}
$$

The small gain in efficiency due to the neutral speed is generally neglected. Neutral-gain utilization is plotted in Fig. B1 for $Q=1$ and $Q=3$, where it is shown to increase with reduced mass utilization and large neutral speed. Thrusters with a high neutral thermal speed or large axial injection speed may exhibit neutral-gain utilization of greater than 1.01-1.02. Mass utilization of Hall thrusters typically ranges from 0.80 to 0.90 for nominal operation. For estimates of $y_{0} \approx 0.03$ [44], the neutral-gain utilization is approximately 1.006 when mass utilization is 0.90 . The neutral gain is expected to be larger for low-discharge voltage, high-power operation where the value of $y_{0}$ is increased and ionization is reduced.

\section{Appendix C: Comparison of Momentum-Weighted and Charge-Weighted Plume Divergence}

The momentum-weighted average divergence is approximated as the charge-weighted average divergence in Eq. (26), which enables calculation of off-axis cosine losses using the ratio of the axial component of beam current to total beam current as measured by a Faraday probe.

Analysis of the ratio $\dot{m}(\theta) v(\theta) / J(\theta)$ introduced in Eq. (26) characterizes the properties that cause differences between momentumweighted divergence and charge-weighted divergence. The ratio is evaluated at angular position $\theta$ in Eq. (C1). Each particle species is approximated with a delta function velocity distribution and velocity ratios are calculated for the idealized case of ion creation at the same location. The ratio $\dot{m}(\theta) v(\theta) / J(\theta)$ is characterized using the dimensionless quantity $\gamma$, which describes differences associated with ionization fraction and ion species population. The term $\gamma$ is shown as a function of $\Phi_{m}, \Phi_{P}, \chi, y_{0}$, and $y_{0}$ in Eq. (C2):

$$
\begin{aligned}
& \frac{\dot{m}(\theta) \bar{v}(\theta)}{J(\theta)}=\left.\frac{\sum_{j=0} \dot{m}_{j} v_{j}}{\sum_{j=1} \dot{m}_{j} Z_{j}(\mathcal{F} / \mathcal{M})}\right|_{\theta} \\
& =\left.\frac{\dot{m}_{T} \Phi_{m}\left|v_{1}\right| \sum_{j=0} f_{j}^{*} y_{j}}{\dot{m}_{T} \Phi_{m} Q(\mathcal{F} / \mathcal{M})}\right|_{\theta}=\left.\left(2 V_{a} \frac{\mathcal{M}}{\mathcal{F}}\right)^{1 / 2} \gamma\right|_{\theta} \\
& \gamma=\frac{\sum_{j=0} f_{j}^{*} y_{j}}{Q}=\left(\frac{\Phi_{P}}{\chi}\right)^{1 / 2}\left[1+\frac{y_{0}^{2}\left(1-\Phi_{m}\right)}{\chi}\right]^{1 / 2} \approx Q^{-1 / 2}
\end{aligned}
$$

The term inside the brackets of Eq. (C2) is near unity for $y_{0} \approx 0.03$, and variations in the neutral speed ratio have negligible effect on $\gamma$. In Fig. $\mathrm{C} 1, \gamma$ is shown for unity mass utilization and $y_{0}=0.03$. The ratio is bounded for a trimodal ion population and is shown to be primarily a function of average ion charge.

Variations in the magnitude of $Q$ alter $\gamma$, but the angular location of these variations is the dominant factor causing differences between momentum-weighted divergence and charge-weighted divergence. This effect is illustrated in Fig. C2, which shows a representative distribution of current density and beam current as a function of angular position for the $6 \mathrm{~kW}$ laboratory Hall thruster from Sec. IV operating at $300 \mathrm{~V}$. The location of peak beam current in the plume is approximately $8 \mathrm{deg}$ from thruster centerline, and variations in $Q$ within the angular range of full-width half-maximum will have the greatest effect on divergence. For the beam current in Fig. C2, this range is approximately \pm 3 to $\pm 21 \mathrm{deg}$. Near- and far-field plume measurements of the $6 \mathrm{~kW}$ Hall thruster [64], the SPT-100 [45,66], and the BHT-200 [73] Hall thruster found that the ion species populations did not significantly change within \pm 15 deg from thruster centerline, and the fraction of $\mathrm{Xe}^{+2}$ increased sharply by

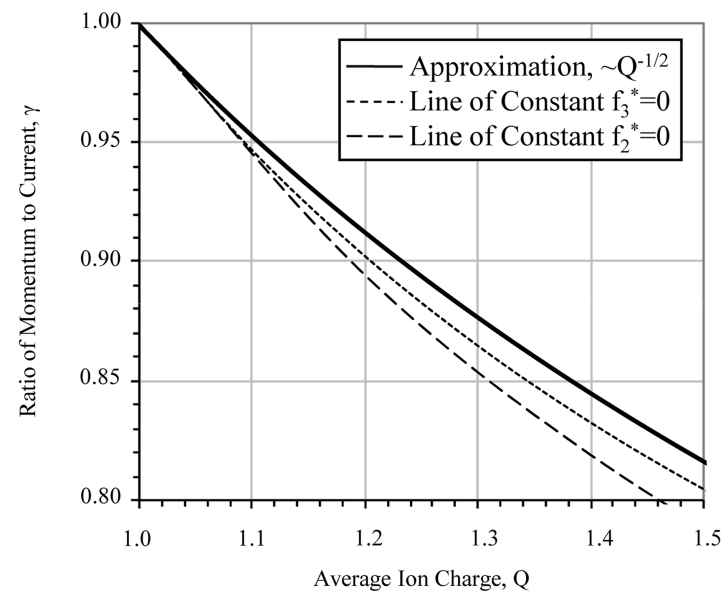

Fig. C1 Variation in $\gamma$ due to average ion charge for $\Phi_{m}=1$ and $y_{0}=0.03$. Lines of constant $f_{2}^{*}=0$ and $f_{3}^{*}=0$ bound $\gamma$ for increased multiply charged ions in a trimodal ion population and are compared with the approximation $\gamma \approx Q^{-1 / 2}$.

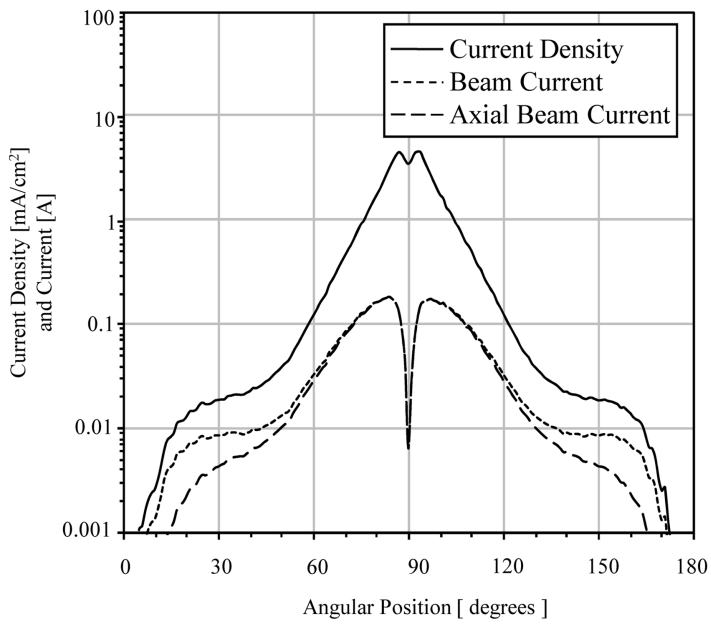

Fig. C2 Representative distribution of beam current and current density at $1 \mathrm{~m}$ radius as a function of angular position in the plume of a nominal $6 \mathrm{~kW}$ laboratory Hall thruster operating at $300 \mathrm{~V}, 10 \mathrm{mg} / \mathrm{s}$ from Sec. IV.

approximately $5 \%$ at $\pm 20 \mathrm{deg}$. These changes in ion species composition have a negligible effect on the value of $\langle\cos (\theta)\rangle_{m v}$, thus enabling the approximation of equivalence between momentumweighted divergence and charge-weighted plume divergence as measured with a Faraday probe.

\section{Appendix D: Propagation of Uncertainty in Performance Parameters and Utilization Efficiencies}

The interrelated expressions for utilization efficiencies and thruster performance parameters necessitate careful examination of the uncertainty. In several expressions, including the total thruster efficiency and propellant efficiency, measured quantities used to calculate the utilization efficiencies will cancel when combined to compute a new term, and the uncertainty should not be considered. The propagation of uncertainty is based on the National Institute of Standards and Technology Technical Note 1297 [74], which is a summary of the comprehensive ISO Guide to the Expression of Uncertainty in Measurement [65].

For uncorrelated terms where the covariance is zero, the propagation of uncertainty is calculated using the square root of the sum of the squared relative error according to Eq. (D1), where $y$ is the measurand and $x$ is the independent variable: 


$$
\begin{gathered}
\left(\frac{\Delta(y)}{y}\right)^{2}=\sum_{j=1}\left(\frac{\delta y}{\delta x_{j}}\right)^{2}\left(\frac{\Delta\left(x_{j}\right)}{x_{j}}\right)^{2} \\
y=f\left(x_{1}, x_{2}, \ldots\right)+\text { constant }
\end{gathered}
$$

For correlated terms, the estimation of uncertainty is more difficult. These variables include the species current fractions (where $\left.\sum \Omega_{j}=1\right)$ and the axial and total integrated ion beam current. The error associated with these terms is examined in closer detail to analytically determine the range of uncertainty.

Ion current fractions are used for the calculation of average charge in Eq. (D3) and for charge utilization in Eq. (D4). The uncertainty of these terms is reduced to a function of uncertainty in the ion current fractions in Eqs. (D5) and (D6):

$$
\begin{gathered}
Q \pm \Delta(Q)=\left(\sum_{j=1} \frac{\Omega_{j} \pm \Delta\left(\Omega_{j}\right)}{Z_{j}}\right)^{-1} \\
\Phi_{q} \pm \Delta\left(\Phi_{q}\right)=\frac{\left[\sum_{j=1}\left\{\left[\Omega_{j} \pm \Delta\left(\Omega_{j}\right)\right] / \sqrt{Z_{j}}\right\}\right]^{2}}{\sum_{j=1}\left\{\left[\Omega_{j} \pm \Delta\left(\Omega_{j}\right)\right] / Z_{j}\right\}} \\
1 \pm \frac{\Delta(Q)}{Q}=\frac{1}{1+Q \sum_{j=1}^{Z}\left\{\left[\mp \Delta\left(\Omega_{j}\right)\right](Z-j) /(j Z)\right\}} \\
1 \pm \frac{\Delta\left(\Phi_{q}\right)}{\Phi_{q}} \\
\approx \frac{1+2\left(Q / \Phi_{q}\right)^{1 / 2} \sum_{j=1}^{Z}\left\{\left[ \pm \Delta\left(\Omega_{j}\right)\right][(1 / \sqrt{j})-(1 / \sqrt{Z})]\right\}}{1+Q \sum_{j=1}^{Z}\left\{\left[ \pm \Delta\left(\Omega_{j}\right)\right](Z-j) /(j Z)\right\}}
\end{gathered}
$$

These conservative formulations of relative error are derived by estimating the deviation when the uncertainty is subtracted from the current fraction of lower ion charge states and is added to the fraction of the highest charge state. Thus, for a bimodal ion population, the uncertainty in the $\mathrm{Xe}^{+}$current fraction is subtracted from $\Omega_{1}$ and added to $\Omega_{2}$. The ion charge state $Z$ in Eqs. (D5) and (D6) corresponds to the highest measured charge state. The approximation in Eq. (D6) is a result of neglecting second-order uncertainty terms and is expected to reduce the overall uncertainty by less than 1 in 1000 .

In many of the utilization efficiency and performance parameter calculations, the effect of multiply charged ions reduces to the ratio of charge utilization with respect to average ion charge. Because these quantities are correlated, it is preferable to analytically estimate the range of uncertainty. The expression in Eq. (D7) is also formulated by neglecting second-order error effects, and the range of uncertainty is less than would be computed for treatment of $Q$ and $\Phi_{q}$ separately based on Eqs. (D5) and (D6):

$$
\frac{\Delta\left(\Phi_{q} / Q\right)}{\left(\Phi_{q} / Q\right)} \approx 2\left(\frac{\Phi_{q}}{Q}\right)^{-1 / 2} \sum_{j=1}^{Z}\left(\frac{1}{\sqrt{j}}-\frac{1}{\sqrt{Z}}\right) \Delta\left(\Omega_{j}\right)
$$

The correlated error between the axial ion current and total ion beam current is difficult to quantify due to facility effects. Systematic error associated with outward scattering and facility effects will be larger for the axial component of beam current. Whereas the individual uncertainties were estimated as $\Delta\left(I_{\text {Beam }}\right)= \pm 6 \%$ and $\Delta\left(I_{\text {Axial }}\right)= \pm 10 \%$, the uncertainty of the ratio is estimated as $\pm 10 \%$ in Eq. (D8) based on experimental measurements over a wide range of distances and background pressures [2]:

$$
\frac{\Delta\left(I_{\text {Axial }} / I_{\text {Beam }}\right)}{\left(I_{\text {Axial }} / I_{\text {Beam }}\right)} \approx 0.10
$$

All other parameters are considered uncorrelated, and relative errors are propagated based on the uncertainty of experimental measurements and/or the uncertainty of correlated values in Eqs. (D3D8):

$$
\frac{\Delta\left(\Phi_{m}\right)}{\Phi_{m}}=\sqrt{\left(\frac{\Delta\left(I_{\text {Beam }}\right)}{I_{\text {Beam }}}\right)^{2}+\left(\frac{\Delta(Q)}{Q}\right)^{2}+\left(\frac{\Delta\left(\dot{m}_{T}\right)}{\dot{m}_{T}}\right)^{2}}
$$

$$
\begin{aligned}
& \frac{\Delta\left(\Phi_{N-G}\right)}{\Phi_{N-G}-1} \\
& \approx \sqrt{\left(\frac{\Delta\left(y_{0}\right)}{y_{0}}\right)^{2}+4\left(\frac{\Delta\left(\Phi_{m}\right)}{\Phi_{m}}\right)^{2}+\frac{1}{4}\left(\frac{\Delta(Q)}{Q}\right)^{2}+\frac{1}{4}\left(\frac{\Delta\left(\Phi_{q}\right)}{\Phi_{q}}\right)^{2}}
\end{aligned}
$$

$$
\begin{aligned}
& \frac{\Delta\left(\Phi_{P}\right)}{\Phi_{P}} \\
& \approx \sqrt{\left(\frac{\Delta\left(I_{\text {Beam }}\right)}{I_{\text {Beam }}}\right)^{2}+\left(\frac{\Delta\left(\dot{m}_{T}\right)}{\dot{m}_{T}}\right)^{2}+\left(\frac{\Delta\left(\Phi_{N-G}\right)}{\Phi_{N-G}-1}\right)^{2}+\left(\frac{\Delta\left(\Phi_{q} / Q\right)}{\left(\Phi_{q} / Q\right)}\right)^{2}}
\end{aligned}
$$

$$
\frac{\Delta\left(\Psi_{B}\right)}{\Psi_{B}}=\sqrt{4\left(\frac{\Delta\left(I_{\text {Axial }} / I_{\text {Beam }}\right)}{\left(I_{\text {Axial }} / I_{\text {Beam }}\right)}\right)^{2}}
$$

$$
\begin{aligned}
& \frac{\Delta(\lambda)}{\lambda}=\sqrt{\left[\frac{\delta\left(\cos ^{-1}\left(I_{\text {Axial }} / I_{\text {Beam }}\right)\right)}{\delta\left(I_{\text {Axial }} / I_{\text {Beam }}\right)}\right]^{2}\left(\frac{\Delta\left(I_{\text {Axial }} / I_{\text {Beam }}\right)}{\lambda}\right)^{2}} \\
& =\frac{\left[\Delta\left(I_{\text {Axial }} / I_{\text {Beam }}\right)\right] / \lambda}{\sqrt{1-\left(I_{\text {Axial }} / I_{\text {Beam }}\right)^{2}}}
\end{aligned}
$$

$$
\frac{\Delta(1-\beta)}{(1-\beta)}=\sqrt{\left(\frac{\Delta\left(V_{a}\right)}{V_{a}}\right)^{2}+\left(\frac{\Delta\left(V_{d}\right)}{V_{d}}\right)^{2}}
$$

$$
\frac{\Delta(1-r)}{(1-r)}=\sqrt{\left(\frac{\Delta\left(I_{\text {Beam }}\right)}{I_{\text {Beam }}}\right)^{2}+\left(\frac{\Delta\left(I_{d}\right)}{I_{d}}\right)^{2}}
$$

$$
\frac{\Delta\left(\eta_{E}\right)}{\eta_{E}}=\sqrt{\left(\frac{\Delta\left(V_{a}\right)}{V_{a}}\right)^{2}+\left(\frac{\Delta\left(V_{d}\right)}{V_{d}}\right)^{2}+\left(\frac{\Delta\left(I_{\text {Beam }}\right)}{I_{\text {Beam }}}\right)^{2}+\left(\frac{\Delta\left(I_{d}\right)}{I_{d}}\right)^{2}}
$$

Thruster performance metrics and experimental parameter groups may be calculated using thrust measurements or plume measurements. Expressions for uncertainty based on plume measurements are listed in Eqs. (D17-D20). Uncertainty using thrust measurements are listed in Eqs. (D21-D24). The mass exchange parameter is computed based solely on telemetry data, and relative error is calculated using Eq. (D25): 


$$
\frac{\Delta\left(E_{1}\right)}{E_{1}}=\sqrt{4\left(\frac{\Delta\left(\dot{m}_{T}\right)}{\dot{m}_{T}}\right)^{2}+4\left(\frac{\Delta\left(I_{\text {Axial }}\right)}{I_{\text {Axial }}}\right)^{2}+\left(\frac{\Delta\left(V_{d}\right)}{V_{d}}\right)^{2}+\left(\frac{\Delta\left(V_{a}\right)}{V_{a}}\right)^{2}+\left(\frac{\Delta\left(\Phi_{N-G}\right)}{\Phi_{N-G}-1}\right)^{2}+\left(\frac{\Delta\left(\Phi_{q} / Q\right)}{\left(\Phi_{q} / Q\right)}\right)^{2}}
$$

$$
\frac{\Delta\left(I_{\mathrm{sp}}\right)}{I_{\mathrm{sp}}}=\sqrt{\left(\frac{\Delta\left(\dot{m}_{T}\right)}{\dot{m}_{T}}\right)^{2}+\left(\frac{\Delta\left(I_{\text {Axial }}\right)}{I_{\text {Axial }}}\right)^{2}+\frac{1}{4}\left(\frac{\Delta\left(V_{a}\right)}{V_{a}}\right)^{2}+\frac{1}{4}\left(\frac{\Delta\left(\Phi_{N-G}\right)}{\Phi_{N-G}-1}\right)^{2}+\frac{1}{4}\left(\frac{\Delta\left(\Phi_{q} / Q\right)}{\left(\Phi_{q} / Q\right)}\right)^{2}}
$$

$$
\frac{\Delta\left(T / P_{d}\right)}{\left(T / P_{d}\right)}=\sqrt{\left(\frac{\Delta\left(V_{d}\right)}{V_{d}}\right)^{2}+\left(\frac{\Delta\left(I_{d}\right)}{I_{d}}\right)+\left(\frac{\Delta\left(I_{\text {Axial }}\right)}{I_{\text {Axial }}}\right)^{2}+\frac{1}{4}\left(\frac{\Delta\left(V_{a}\right)}{V_{a}}\right)^{2}+\frac{1}{4}\left(\frac{\Delta\left(\Phi_{N-G}\right)}{\Phi_{N-G}-1}\right)^{2}+\frac{1}{4}\left(\frac{\Delta\left(\Phi_{q} / Q\right)}{\left(\Phi_{q} / Q\right)}\right)^{2}}
$$

$$
\frac{\Delta\left(\eta_{T}\right)}{\eta_{T}}=\sqrt{\left(\frac{\Delta\left(\dot{m}_{T}\right)}{\dot{m}_{T}}\right)^{2}+\left(\frac{\Delta\left(V_{d}\right)}{V_{d}}\right)^{2}+\left(\frac{\Delta\left(I_{d}\right)}{I_{d}}\right)+4\left(\frac{\Delta\left(I_{\text {Axial }}\right)}{I_{\text {Axial }}}\right)^{2}+\left(\frac{\Delta\left(V_{a}\right)}{V_{a}}\right)^{2}+\left(\frac{\Delta\left(\Phi_{N-G}\right)}{\Phi_{N-G}-1}\right)^{2}+\left(\frac{\Delta\left(\Phi_{q} / Q\right)}{\left(\Phi_{q} / Q\right)}\right)^{2}}
$$

$$
\begin{gathered}
\frac{\Delta\left(E_{1}\right)}{E_{1}}=\sqrt{4\left(\frac{\Delta(T)}{T}\right)^{2}+4\left(\frac{\Delta\left(\dot{m}_{T}\right)}{\dot{m}_{T}}\right)^{2}+\left(\frac{\Delta\left(V_{d}\right)}{V_{d}}\right)^{2}} \\
\frac{\Delta\left(I_{\mathrm{sp}}\right)}{I_{\mathrm{sp}}}=\sqrt{\left(\frac{\Delta\left(\dot{m}_{T}\right)}{\dot{m}_{T}}\right)^{2}+\left(\frac{\Delta(T)}{T}\right)^{2}} \\
\frac{\Delta\left(T / P_{d}\right)}{\left(T / P_{d}\right)}=\sqrt{\left(\frac{\Delta\left(V_{d}\right)}{V_{d}}\right)^{2}+\left(\frac{\Delta\left(I_{d}\right)}{I_{d}}\right)^{2}+\left(\frac{\Delta(T)}{T}\right)^{2}}
\end{gathered}
$$

$$
\frac{\Delta\left(\eta_{T}\right)}{\eta_{T}}=\sqrt{\left(\frac{\Delta\left(V_{d}\right)}{V_{d}}\right)^{2}+\left(\frac{\Delta\left(I_{d}\right)}{I_{d}}\right)^{2}+\left(\frac{\Delta\left(\dot{m}_{T}\right)}{\dot{m}_{T}}\right)^{2}+4\left(\frac{\Delta(T)}{T}\right)^{2}}
$$

$$
\frac{\Delta\left(E_{2}\right)}{E_{2}}=\sqrt{\left(\frac{\Delta\left(\dot{m}_{T}\right)}{\dot{m}_{T}}\right)^{2}+\left(\frac{\Delta\left(I_{d}\right)}{I_{d}}\right)^{2}}
$$

\section{Acknowledgments}

The authors acknowledge numerous insightful discussions with Justin Koo, Michelle Scharfe, Bill Hargus, and James Haas that contributed to development of the ideas and concepts presented in this paper.

\section{References}

[1] Semenkin, A., Kim, V., Gorshkov, O., and Jankovsky, R., "Development of Electric Propulsion Standards: Current Status and Further Activity," International Electric Propulsion Conference Paper 2001-70, 2001.

[2] Brown, D. L., "Investigation of Low Discharge Voltage Hall Thruster Characteristics and Evaluation of Loss Mechanisms," Ph.D. Dissertation, Univ. of Michigan, Ann Arbor, MI, 2009.

[3] Morozov, A. I., "About Plasma Acceleration by Magnetic Fields," Journal of Experimental and Theoretical Physics, Vol. 32, No. 2, 1957, p. 305 (in Russian).

[4] Yushmanov, E. E., "Radial Distribution of the Potential in Cylindrical
Trap with Magnetron Ion Injection," Plasma Physics and the Problem of Controlled Fusion, Vol. 4, edited by M. A. Leontovich, USSR Academy of Science, Moscow, 1958 (in Russian).

[5] Zharinov, A. V., Electric Double Layer in Strong Magnetic Field, Kurchatov Inst. Rept., Moscow, 1961 (in Russian).

[6] Lary, E. C., Meyerand, R. G., Jr., and Salz, F., "Ion Acceleration in a Gyro-Dominated Neutral Plasma: Theory and Experiment," Bulletin of the American Physical Society, Series II, Vol. 7, July 1962, p. 441.

[7] Seikel, G. R., and Reshotko, E., "Hall-Current Ion Accelerator," Bulletin of the American Physical Society, Series II, Vol. 7, July 1962, p. 414.

[8] Janes, G. S., Dotson, J., and Wilson, T., "Electrostatic Acceleration of Neutral Plasmas: Momentum Transfer Through Magnetic Fields," Proceedings of the Third Symposium on Advanced Propulsion Concepts, Gordon and Breach Science Publishers, New York, 1963, pp. 153-175.

[9] Brown, C. O., and Pinsley, E. A., "Further Experimental Investigations of a Cesium Hall-Current Accelerator," AIAA Journal, Vol. 3, No. 5, 1965, pp. 853-859. doi: $10.2514 / 3.3006$

[10] Morozov, A. I., "Investigation of the Stationary Electromagnetic Plasma Acceleration," Ph.D. Thesis, Inst. of Atomic Energy, Moscow, 1965 (in Russian).

[11] Janes, G. S., and Lowder, R. S., "Anomalous Electron Diffusion and Ion Acceleration in a Low-Density Plasma," Physics of Fluids, Vol. 9, No. 6, 1966, pp. 1115-1123. doi:10.1063/1.1761810.

[12] Zharinov, A. V., and Popov, Y. S., "Acceleration of Plasma by a Closed Hall Current," Soviet Physics-Technical Physics, Vol. 12, No. 2, Aug. 1967, pp. 208-211 (in Russian).

[13] Morozov, A. I., "Wall Conduction in a Highly Magnetized Plasma," Journal of Applied Mechanics and Technical Physics, Vol. 9, No. 3, 1968, pp. 19-22 (in Russian).

[14] Kaufman, H. R., "Technology of Closed-Drift Thrusters," AIAA Journal, Vol. 23, No. 1, 1985, pp. 78-87. doi: $10.2514 / 3.8874$

[15] Zhurin, V. V., Kaufman, H. R., and Robinson, R. S., "Physics of Closed Drift Thrusters," Plasma Sources, Science and Technology, Vol. 8, No. 1, 1999, pp. R1-R20. doi:10.1088/0963-0252/8/1/021

[16] Morozov, A. I., "The Conceptual Development of Stationary Plasma Thrusters," Plasma Physics Reports, Vol. 29, No. 3, 2003, pp. 235-250 (translated from Fizika Plazmy, Vol. 29, No. 3, 2003, pp. 261-276). doi:10.1134/1.1561119

[17] Kim, V., "History of the Hall Thrusters Development in USSR," International Electric Propulsion Conference Paper 2007-142, 2007.

[18] Masek, T. D., Ward, J. W., and Kami, S., "Primary Electric Propulsion Thrust Subsystem Definition," AIAA Paper 75-405, 1975.

[19] Brophy, J. R., "Stationary Plasma Thruster Evaluation in Russia," Jet Propulsion Lab. Publ. 92-4, NASA CR-192823, 15 March 1992.

[20] Garner, C. E., Brophy, J. R., Polk, J. E., Semenkin, S., Garkusha, V., Tverdokhlebov, S., and Marrese, C., "Experimental Evaluation of 
Russian Anode Layer Thrusters,” AIAA Paper 1994-3010, 1994

[21] Meyer, R. M., and Manzella, D. H., "SPT Thruster Plume Characteristics," International Electric Propulsion Conference Paper 93-096, 1993.

[22] Sankovic, J. M., Hamley, J. A., and Haag, T. W., "Performance Evaluation of the Russian SPT-100 Thruster at NASA LeRC," International Electric Propulsion Conference Paper 93-094, 1993.

[23] Garner, C. E., Polk, J. E., Goodfellow, K. D., and Brophy, J. R., "Performance Evaluation on Life Testing of the SPT-100," International Electric Propulsion Conference Paper 93-091, 1993.

[24] King, L. B., Gallimore, A. D., and Marrese, C. M., "Transport-Property Measurements in the Plume of an SPT-100 Hall Thruster," Journal of Propulsion and Power, Vol. 14, No. 3, 1998, pp. 327-335. doi:10.2514/2.5301

[25] Belan, N. V., Kim, V. P., Oransky, A. I., and Tikhonov, V. B., "Stationary Plasma Engines," Kharkov Aviation Inst., Kharkov, Ukraine, 1989, pp. 164-166 (in Russian).

[26] Bugrova, A. I., Kim, V. P., Maslennikov, N. A., and Morozov, A. I., "Physical Properties and Characteristics of Stationary Plasma Thrusters with Closed Electron Drift," International Electric Propulsion Conference Paper 91-079, 1991.

[27] Kim, V., "Main Physical Features and Processes Determining the Performance of Stationary Plasma Thrusters," Journal of Propulsion and Power, Vol. 14, No. 5, Sept.-Oct. 1998, pp. 736-743. doi: $10.2514 / 2.5335$

[28] Morozov, A. I., Bugrova, A. I., Desyatskov, A. V., Ermakov, Y. A., Kozintseva, M. V., Lipatov, A. S., Pushkin, A. A., Khartchevnikov, V. K., and Banov, D. V., "ATON-Thruster Plasma Accelerator," Plasma Physics Reports, Vol. 23, No. 7, 1997, pp. 587-597 (translated from Fizika Plazmy, Vol. 23, No. 7, 1997, pp. 635-645).

[29] Bugrova, A. I., Lipatov, A. S., Morozov, A. I., and Baranov, S. V., "Effect of the Ratio of Differently Charged Ions on the Integral Parameters of Stationary Plasma Thrusters of the ATON Type," Technical Physics Letters, Vol. 31, No. 11, 2005, pp. 943-946 (translated from Pis 'ma v Zhurnal Tekhnicheskoi Fiziki, Vol. 31, No. 21, 2005, pp. 87-94). doi: $10.1134 / 1.2136960$

[30] Bouchoule, A., Boeuf, J. P., Heron, A., and Duchemin, O., "Physical Investigations and Developments of Hall Plasma Thrusters," Plasma Physics and Controlled Fusion, Vol. 46, No. 12b, 2004, pp. B407B421. doi:10.1088/0741-3335/46/12B/035

[31] Grishin, S. D., and Leskov, L. V., Electrical Rocket Engines of Space Vehicles, Mashinostroyeniye, Moscow, 1989, p. 12

[32] Raitses, Y., Ashkenazy, J., and Guelman, M., "Propellant Utilization in Hall Thrusters," Journal of Propulsion and Power, Vol. 14, No. 2, 1998, pp. $247-253$. doi:10.2514/2.5274

[33] Raitses, Y., and Fisch, N. J., "Parametric Investigations of a Nonconventional Hall Thruster," Physics of Plasmas Vol. 8, No. 5, 2001, pp. 2579-2586. doi:10.1063/1.1355318

[34] Sasoh, A., "Generalized Hall Acceleration," Journal of Propulsion and Power, Vol. 10, No. 2, 1994, pp. 251-254. doi: $10.2514 / 3.23736$

[35] Bober, A., "Numerical Analysis of Hall Thruster Firing Tests," Journal of Propulsion and Power, Vol. 23, No. 3, May-June 2007, pp. 537543. doi: $10.2514 / 1.24525$

[36] Linnell, J. A., and Gallimore, A. D., "Efficiency Analysis of a Hall Thruster Operating with Krypton and Xenon," Journal of Propulsion and Power, Vol. 22, No. 6, 2006, pp. 1402-1418. doi: $10.2514 / 1.19613$

[37] Fife, J. M., and Martinez-Sanchez, M., "Two-Dimensional Hybrid Particle-In-Cell Modeling of Hall Thrusters," International Electric Propulsion Conference Paper 95-240, 1995.

[38] Komurasaki, K., and Arakawa, Y., "Hall Current Ion-Thruster Performance," Journal of Propulsion and Power, Vol. 8, No. 6, 1992, pp. 1212-1216. doi: $10.2514 / 3.11464$

[39] Ahedo, E., Gallardo, J. M., and Martinez-Sanchez, M., "Model of the Plasma Discharge in a Hall Thruster with Heat Conduction," Physics of Plasmas, Vol. 9, No. 9, 2002, pp. 4061-4070. doi: $10.1063 / 1.1499496$

[40] Hofer, R. R., and Gallimore, A. D., "High-Specific Impulse Hall Thrusters, Part 2: Efficiency Analysis," Journal of Propulsion and Power, Vol. 22, No. 4, 2006, pp. 732-740. doi:10.2514/1.15954

[41] Hofer, R. R., Katz, I., Mikellides, I. G., Goebel, D. M., Jameson, K. K., Sullivan, R. M., and Johnson, L. K., "Efficacy of Electron Mobility
Models in Hybrid-PIC Hall Thruster Simulations,” AIAA Paper 20084924, 2008

[42] Longmier, B. W., Reid, B. M., Gallimore, A. D., Chang-Diaz, F. R., Squire, J. P., Glover, T. W., Chavers, G., and Bering, E. A., III, "Validating a Plasma Momentum Flux Sensor to an Inverted Pendulum Thrust Stand," Journal of Propulsion and Power, Vol. 25, No. 3, 2009, pp. 746-752.

doi: $10.2514 / 1.35706$

[43] Hargus, W. A., Jr., and Cappelli, M. A., "Interior and Exterior LaserInduced Fluorescence and Plasma Measurements Within a Hall Thruster," Journal of Propulsion and Power, Vol. 18, No. 1, 2002, pp. $159-168$. doi: $10.2514 / 2.5912$

[44] Smith, T. B., Huang, W., Reid, B. M., and Gallimore, A. D., "Near-Field Laser-Induced Fluorescence Velocimetry of Neutral Xenon in a $6 \mathrm{~kW}$ Hall Thruster Plume," International Electric Propulsion Conference Paper 2007-252, 2007.

[45] Kim, S. W., and Gallimore, A. D., "Plume Study of a 1.35-kW SPT-100 Using an ExB Probe," Journal of Spacecraft and Rockets, Vol. 39, No. 6, 2002, pp. 904-909. doi: $10.2514 / 2.3897$

[46] King, L. B., "Transport-Property and Mass Spectral Measurements in the Exhaust Plume of a Hall Effect Space Propulsion System," Ph.D. Dissertation, Univ. of Michigan, Ann Arbor, MI, 1998

[47] Hofer, R. R., "Development and Characterization of High-Efficiency, High Specific Impulse Xenon Hall Thrusters," Ph.D. Dissertation, Univ. of Michigan, Ann Arbor, MI, 2004; Published as NASA CR-2004213099, 2004.

[48] Masek, T. D., "Plasma Properties and Performance of Mercury Ion Thrusters," AIAA Journal, Vol. 9, No. 2, 1971, pp. 205-212. doi: $10.2514 / 3.6152$

[49] Goebel, D. M., and Katz, I., Fundamentals of Electric Propulsion: Ion and Hall Thrusters, Wiley, New York, 2007.

[50] Morozov, A. I., Physical Principles of Cosmic Electric Propulsion Engines, Atomizdat, Moscow, 1978.

[51] Morozov, A. I., Balebanov, V. M., Bugrova, A. I., Lipatov, A. S., and Khartchevnikov, V. K., "ATON-Thruster Plasma Accelerator," 4th AllRussian Seminar on Problems of Theoretical and Applied Electron Optics, Proceedings of SPIE, Vol. 4187, International Society for Optical Engineering, Bellingham, WA, 2000, pp. 70-78.

[52] Bugrova, A. I., Lipatov, A. S., Morozov, A. I., and Churbanov, D. V., "On Similarity Criterion for Plasma Accelerators of the Stationary Plasma Thruster Type," Technical Physics Letters, Vol. 28, No. 10, 2002, pp. 821-823 (translated from Pis 'ma v Zhurnal Tekhnicheskoi Fiziki, Vol. 28, No. 19, 2002, pp. 821-823). doi:10.1134/1.1519018

[53] Larson, C. W., Brown, D. L., and Hargus, W. A., Jr., "Thrust Efficiency, Energy Efficiency and the Role of the VDF in Hall Thruster Performance Analysis," AIAA Paper 2007-5270, 2007.

[54] Brown, D. L., Larson, C. W., Haas, J. M., and Gallimore, A. D. "Analytical Extraction of Plasma Properties Using a Hall Thruster Efficiency Architecture," International Electric Propulsion Conference Paper 2007-188, 2007.

[55] Mirels, H., and Rosenbaum, B. M., "Analysis of One-Dimensional Ion Rocket," NASA TN D-266, 1960.

[56] Kaufman, H. R., "One-Dimensional Analysis of Ion Rockets," NASA TN D-261, 1960.

[57] Byers, D. C., "Angular Distribution of Kaufman Ion Thruster Beams," NASATN D-5844, 1970.

[58] Nieberding, W. C., Lesco, D. J., and Berkopec, F. D., "Comparative InFlight Thrust Measurements of the SERT II Ion Thruster," AIAA Paper 75-405, 1970.

[59] Kerslake, W. R., Goldman, R. G., and Nieberding, W. C., "SERT II: Mission, Thruster Performance, and In-Flight Thrust Measurements," Journal of Spacecraft and Rockets, Vol. 8, No. 3, March 1971, pp. 213 224. doi:10.2514/3.30250

[60] Banks, B., Rawlin, V., Weigand, A., and Walker, J., "Direct Thrust Measurement of a 30-cm Ion Thruster," NASA TM X-71646.

[61] Brophy, J. R., "NASA's Deep Space 1 Ion Engine (Plenary)," Review of Scientific Instruments, Vol. 73, No. 2, Feb. 2002, pp. 1071-1078. doi:10.1063/1.1432470

[62] Reid, B. M., "The Influence of Neutral Flow Rate in the Operation of Hall Thrusters," Ph.D. Dissertation, Univ. of Michigan, Ann Arbor, MI, 2009.

[63] Shastry, R., Hofer, R. R., Reid, B. M., and Gallimore, A. D., "Method for Analyzing ExB Probe Spectra from Hall Thruster Plumes," AIAA Paper 2008-4647, 2008

[64] Reid, B. M., Shastry, R., Gallimore, A. D., and Hofer, R. R., "Angularly 
Resolved ExB Probe Spectra in the Plume of a 6 kW Hall Thruster," AIAA Paper 2008-5287, 2008.

[65] Guide to the Expression of Uncertainty in Measurement, Joint Publ. of the International Bureau of Weights and Measures, International Electrotechnical Commission, International Federation of Clinical Chemistry, International Organization for Standardization, International Union of Pure and Applied Chemistry, International Union of Pure and Applied Physics, and International Organization of Legal Metrology; prepared by International Organization for Standardization Technical Advisory Group 4, Working Group 3, Oct. 1993.

[66] Kim, S. W., "Experimental Investigations of Plasma Parameters and Species-Dependent Ion Energy Distribution in the Plasma Exhaust of a Hall Thruster," Ph.D. Dissertation, Univ. of Michigan, Ann Arbor, MI, 1999.

[67] Manzella, D., and Jacobson, D., "Investigation of Low-Voltage/HighThrust Hall Thruster Operation," AIAA Paper 2003-5004; also NASA TM-2003-212699, 20-23 July 2003.

[68] Masek, T. D., "Plasma Properties and Performance of Mercury Ion Thrusters," AIAA Paper 69-256, 1969.

[69] Brophy, J. R., "Ion Thruster Performance Model," Ph.D. Dissertation, Colorado State Univ., Fort Collins, CO, 1984; also NASA CR-174810, 1984.
[70] Ahedo, E., and Escobar, D., "Influence of Design and Operation Parameters on Hall Thruster Performance," Journal of Applied Physics, Vol. 96, No. 2, 2004, pp. 983-992.

[71] Raitses, Y., Staack, D., Smirnov, A., and Fisch, N. J., "Space Charge Saturated Sheath Regime and Electron Temperature Saturation in Hall Thrusters," Physics of Plasmas, Vol. 12, No. 7, 2005, pp. 073507.1073507.10. doi:10.1063/1.1944328

[72] Barral, S., Makowski, K., Peradzynski, Z., Gascon, N., and Dudeck, M., "Wall Material Effects in Stationary Plasma Thrusters, II: Near-Wall and In-Wall Conductivity," Physics of Plasmas, Vol. 10, No. 10, Oct. 2003, pp. 4137-4152. doi:10.1063/1.1611881

[73] Beal, B. E., "Clustering of Hall Effect Thrusters for High Power Electric Propulsion Applications," Ph.D. Dissertation, Univ. of Michigan, Ann Arbor, MI, 2004.

[74] Taylor, B. N., and Kuyatt, C. E., "Guidelines for Evaluating and Expressing the Uncertainty of NIST Measurement Results," National Inst. of Standards and Technology, TN 1297, 1994.

A. Gallimore Associate Editor 